\title{
SiC porous structures obtained with innovative shaping technologies
}

DOI:

10.1016/j.jeurceramsoc.2017.09.048

\section{Document Version}

Accepted author manuscript

Link to publication record in Manchester Research Explorer

\section{Citation for published version (APA):}

Ferraro, C., Garcia-Tunon, E., Barg, S., Miranda, M., Ni, N., Bell, R., \& Saiz, E. (2018). SiC porous structures obtained with innovative shaping technologies. Journal of the European Ceramic Society.

https://doi.org/10.1016/j.jeurceramsoc.2017.09.048

\section{Published in:}

Journal of the European Ceramic Society

\section{Citing this paper}

Please note that where the full-text provided on Manchester Research Explorer is the Author Accepted Manuscript or Proof version this may differ from the final Published version. If citing, it is advised that you check and use the publisher's definitive version.

\section{General rights}

Copyright and moral rights for the publications made accessible in the Research Explorer are retained by the authors and/or other copyright owners and it is a condition of accessing publications that users recognise and abide by the legal requirements associated with these rights.

\section{Takedown policy}

If you believe that this document breaches copyright please refer to the University of Manchester's Takedown Procedures [http://man.ac.uk/04Y6Bo] or contact uml.scholarlycommunications@manchester.ac.uk providing relevant details, so we can investigate your claim.

\section{OPEN ACCESS}




\section{SiC porous structures obtained with innovative shaping technologies}

${ }^{1,}$ Claudio Ferraro*, ${ }^{1,2,3}$ Esther Garcia-Tunon*, ,'Suelen Barg, ${ }^{1}$ Miriam Miranda, ${ }^{1} \mathrm{Na} \mathrm{Ni},{ }^{1,}$ Robert Bell, ${ }^{1}$ Eduardo Saiz (*Eual contribution, corresponding authors)

1, Department of Materials, Imperial College of London, Royal School of Mines, Exhibition Road, SW7 2BP, London, United Kingdom

2, Materials Innovation Factory, University of Liverpool

${ }^{3,}$ School of Engineering, University of Liverpool

4, School of Materials, The University of Manchester

\section{ABSTRACT}

SiC structures with porosities ranging between 20 to $60 \%$ have been fabricated using two methods: emulsification and freeze casting. While emulsification results in foam-like isotropic materials with interconnected pores, freeze casting can be used to fabricate highly anisotropic materials with characteristic layered architectures. The parameters that control the pore size and final porosity have been identified (solid content in the initial suspensions, emulsification times or speed of the freezing front). We have found that liquid state sintering (suing $\mathrm{Al}_{2} \mathrm{O}_{3}$ and $\mathrm{Y}_{2} \mathrm{O}_{3}$ as additives) at $1800{ }^{\circ} \mathrm{C}$ on a powder $\left(\mathrm{SiC} / \mathrm{Al}_{2} \mathrm{O}_{3}\right)$ bed provides optimum consolidation for the porous structures. The mechanical strength of the materials depends on their density. Freeze casted materials fabricated with bimodal particle size distributions (a controlled mixture of micro and nanoparticles) exhibit higher compressive 
strengths that can reach values of up to $280 \mathrm{MPa}$ for materials with densities of 0.47 .

Keywords: porous materials, $\mathrm{SiC}$, freeze casting, emulsions, strength, thermal conductivity.

\section{INTRODUCTION}

The advance of key technological fields like transportation, building, energy or healthcare depends on the development of novel lightweight porous materials capable of providing exceptional mechanical performance under demanding environments, from high temperatures to corrosive media. Applications such as catalysis supports, filters, separation membranes or thermal insulators, require porous structures able to combine structural stability with high surface area, control of internal fluid flow and tailored thermal or electrical conductivities. Silicon carbide is a ceramic with outstanding mechanical, thermal and chemical properties (such as thermal shock and corrosion resistance) making it a promising candidate for many of these applications, in particular those that involve work under extreme environments [1].

The fabrication of porous $\mathrm{SiC}$ ceramics requires manufacturing techniques able to provide strong and stable structures with good architectural control from micro to macro levels. Sintering is particularly challenging. The covalent nature of the bond between $\mathrm{Si}$ and $\mathrm{C}$ atoms provides outstanding structural properties to SiC but at the same time results in very low sinterability. Sintering, either solid $[2,3]$ or liquid phase $[1,4]$ requires different additives and is often carried under pressure [2,5]. However, this is not possible when 
fabricating highly porous structures. Additive formulation and the local atmosphere play a very important role during sintering; boron and carbon are frequently used in solid sintering [2] and a mixture of alumina and yttria for liquid phase sintering $[1,4]$. The final microstructures and mechanical properties are strongly affected by the sintering conditions, being necessary to find a compromise between densification and grain growth. To achieve this goal non-conventional sintering routes such as spark plasma sintering (SPS) have also been used $[5,6]$.

Different assembly and shaping strategies can be considered to control the architecture of porous structures. Some of the available alternatives to produce macroporous SiC use polymeric pre-ceramic precursors $[7,8]$, or combine carbon foams (e.g. wood-derived) with Si sources [7,9]. These approaches overcome partially the sintering challenges but provide limited architectural control. Alternatives such as sacrificial templating usually lead to low cell wall densities and considerable shrinkage and typically require additive contents ranging between $4 w t \%$ to $20 w t \%[1,10,11]$. It is still necessary to develop new processing routes in order to produce macroporous $\mathrm{SiC}$ structures with controlled morphological features at multiple scale lengths, while optimising the sintering conditions to obtain high-density walls that will lead to strong materials.

Freeze casting of ceramic suspensions and the directed assembly of emulsified suspensions are two of the most promising paths for complex shaping and microstructural control. Freeze casting uses the complex structure of ice to create monolithic and hybrid materials that exhibit unique bio-inspired hierarchical structures and very promising properties [12]. It is 
based on the directional freezing of a colloidal suspension at controlled speed to promote the growth of lamellar ice. The growing ice expels the ceramic particles as it grows, arranging and compacting them in walls between adjacent ice crystals [13]. After sublimating the water a porous structure remains that is the replica of the ice. Control of the freezing process is used to tailor the morphological features of this structure over a range of size-scales.

The directed assembly of emulsified suspensions follows a bottom-up approach based on the surface functionalization of inorganic particles with responsive polymers [14]. By engineering the surface of ceramic particles with a pH-responsive macromolecule, it is possible to direct the assembly of these responsive particles and oil droplets into complex hierarchical structures[14,15]. These water-based emulsified suspensions can assemble reversibly with a $\mathrm{pH}$ switch [15] and template the architecture of the final ceramic structures.

Here, we aim to compare the manufacturing and properties of SiC scaffolds with lamellar and foam-like architectures designed by two assembly strategies, i.e. freeze-casting and directed assembly of emulsified suspensions. These techniques can be used to control the final microstructure, in particular to tune porosity and pore shape and size. In this way materials can be tailored for different applications, from layered structures that can be used in the fabrication of microlaminated composites [16] to structures with homogeneously distributed equiaxial pores that can provide thermal insulation or combine light weight with enough compressive strength for some structural applications. We also investigate the best sintering route to preserve the features of the porous architectures while 
optimizing their consolidation. We optimize the sintering conditions by analyzing the effect of temperature, time, and atmosphere under pressureless solid and liquid-phase sintering (SS and LS respectively) in conventional and spark plasma sintering (SPS) furnaces. The dominating factors controlling the different assembly approaches and the correlation between structure, mechanical and functional properties are investigated and characterized by combining Field Emission Scanning Electron Microscopy (FESEM), Transmission Electron Microscopy (TEM) and xRay diffraction (XRD) with mechanical testing, and thermal conductivity measurements.

\section{EXPERIMENTAL}

\subsection{Scaffold manufacturing.}

Direct assembly of emulsified suspensions. SiC scaffolds with foam-like structures were prepared by the directed assembly of emulsified SiC responsive suspensions. Silicon Carbide particles were electrostatic and sterically stabilized by a multifunctional-branched copolymer surfactant (BCS). BCS with a composition of PEGMA ${ }_{5}-\mathrm{MAA}_{95}-\mathrm{EGDMA}_{10}-\mathrm{DDT}_{10}$ was synthesized following the protocol described by Woodward et al. [17]. BCS solutions (1 wt/v\%) were prepared in distilled water at $\mathrm{pH} 12$ (adjusted with $\mathrm{NaOH} 1 \mathrm{M}$ ). Colloidal SiC suspensions (with concentrations of 12 and 33 vol\%) were prepared by dispersing $\alpha$-SiC particles (ABCR-H.C Starck, $d_{50} 450$ $\mathrm{nm}$ and specific surface area of $23-26 \mathrm{~m}^{2} / \mathrm{g}$ ) in the BCS solutions at $\mathrm{pH} 8$, thus enabling the surface functionalization of SiC particles with BCS. For some experiments two types of $\mathrm{SiC}$ particles where mixed $(70 \mathrm{wt} \%$ of particles with an average size of $450 \mathrm{~nm}$ and specific surface area of $23-26 \mathrm{~m}^{2} / \mathrm{g}$ and 
$30 \%$ of SiC nanoparticles, SkySpring Nanomaterials, USA, with an average particle size of $40 \mathrm{~nm}$ and specific surface area $>80 \mathrm{~m}^{2} / \mathrm{g}$ ). These will be called "mixed particle emulsions" from now on. Sintering aids, Boron (Merk $\mathrm{KGaA}$ ) or $\mathrm{Al}_{2} \mathrm{O}_{3}$ (Baikalox B-series SMA6, Baikowski, France) and $\mathrm{Y}_{2} \mathrm{O}_{3}$ (Grade C-ABCR - H.C. Starck) were added to the stabilized SiC suspensions that were subsequently subjected to ball milled for $24 \mathrm{~h}$ (Table 1). Afterwards, the suspensions were conditioned with $1 \mathrm{wt} \%$ octanol and stirred under a light vacuum for 1 hour. Highly stable SiC responsive emulsions were obtained by emulsifying the BCS-functionalized $\mathrm{SiC}$ suspensions at $\mathrm{pH} 8$ with $50 \mathrm{vol} \%$ of decane at speeds between 2000 and 24000 rpm for 2 minutes. In order to promote the assembly of suspensions and emulsions into stable solid structures, their $\mathrm{pH}$ was dropped below the pKa of BCS (6.46) by adding between 2 and $10 \mathrm{wt} / \mathrm{v} \%$ of glucono- $\delta$-lactone (GסL, $\geq 99 \%$, Sigma Aldrich). GסL lowers the $\mathrm{pH}$ in two-steps: dissolution and subsequent hydrolysis of the GסL to gluconic acid. This drop activated multiple hydrogen bonds between the functionalities in BCS and directed the assembly of particles and droplets in the emulsion into very well organized 3D architectures. The SiC architectures were subsequently dried at $35^{\circ} \mathrm{C}$ for 10 days and sintered as described in 2.3 . 
Table 1. Additives and sintering aids added in the water-based slurries used for the fabrication of macroporous SiC scaffolds. TMAH and PVA contents are related to the weight of the SiC particles. Sucrose is related to the water content. BCS content is related to the total volume of water in the suspension.

\begin{tabular}{|c|c|c|c|c|}
\hline & \multirow{2}{*}{ Processing additives } & \multicolumn{2}{|c|}{$\begin{array}{l}\text { Solid State (SS) } \\
\text { sintering aids }\end{array}$} & \multirow{2}{*}{$\begin{array}{l}\text { Liquid State }(\mathrm{LS}) \\
\text { sintering aids }\end{array}$} \\
\hline & & Boron & $\begin{array}{l}\text { Source of } \\
\text { C }\end{array}$ & \\
\hline $\begin{array}{l}\text { Freeze } \\
\text { casting }\end{array}$ & $\begin{array}{l}\text { 1.4wt\% TMAH } \\
1.4 w t \% \text { PVA } \\
4 w t \% \text { sucrose } \\
@ p H 10\end{array}$ & \multirow{2}{*}{$0.35 w t \%$} & $\begin{array}{c}\text { PVA } \\
\text { sucrose }\end{array}$ & \multirow{2}{*}{$\begin{array}{l}\text { Between } 4 \text { and } \\
8 w t \% \text { of an } \\
\text { oxide mixture } \\
\left(6 / 4 \mathrm{Al}_{2} \mathrm{O}_{3} / \mathrm{Y}_{2} \mathrm{O}_{3}\right)\end{array}$} \\
\hline $\begin{array}{l}\text { Directed } \\
\text { assembly }\end{array}$ & $\begin{array}{l}\text { BCS (1wt/v\%) @pH 8-9 } \\
1 \text { wt\% octanol } \\
2-10 w t / v \% \text { GoL }\end{array}$ & & $\begin{array}{l}\text { BCS } \\
\text { GסL }\end{array}$ & \\
\hline
\end{tabular}

The addition of a fluorescent dye to the branched architecture of the responsive copolymer was used to study the BCS-SiC interactions. Standard solutions of BCSr (BCS-rhodamine) with concentrations ranging from 0.001 to $3 \mathrm{wt} / \mathrm{v} \%$ were prepared in distilled water at $\mathrm{pH} 8$ and measured in a UV-visible spectrometer to obtain the calibration curve by plotting the absorbance at $566 \mathrm{~nm}$ vs. concentration. Afterwards, the supernatants of $\mathrm{SiC} / \mathrm{BCSr}$ suspensions containing $10 \mathrm{vol} \% \mathrm{SiC}$ particles and increasing amounts of $\mathrm{BCSr}$ (ranging from 0.01 to $3 \mathrm{wt} / \mathrm{v} \%$ ) were analyzed by UV-visible spectroscopy after centrifugation up to 12000 rpm to quantify BCS adsorption on SiC surfaces.

Freeze casting. For the preparation of SiC scaffolds with lamellar structures, a-SiC colloidal suspensions were prepared by mixing 9 and 20 vol\% of $\alpha-S i C$ (ABCR-H.C Starck, Germany) particles in distilled water. The suspensions were stabilized using TMAH (Tetra-methyl-ammoniumhydroxide, SigmaAldrich). PVA (poly-vinyl-alcohol, PVA 22000, VWR, Belgium) and sucrose (Anala R Normapur, VWR, Belgium) were also added as binders and ice 
shaping agents (Compositions in Table 1) [12]. The suspensions were prepared at $\mathrm{pH} 10$ where $\mathrm{SiC}$ is highly negatively charged in the presence of TMAH. Sintering aids, Boron or $\mathrm{Al}_{2} \mathrm{O}_{3}$ and $\mathrm{Y}_{2} \mathrm{O}_{3}$, were added to the $\mathrm{SiC}$ suspensions prior to ball milling (Table 1) [1]. The suspensions were ball milled for 24 hours with SiC balls and afterwards de-aired by stirring for at least 30 minutes under light vacuum. Once conditioned, the suspensions were directionally frozen by placing them on top of a copper cold finger in a Teflon ${ }^{\circledR}$ mold. The cold finger was cooled at a rate varying between 5 and $15 \mathrm{~K} / \mathrm{min}$. The frozen scaffolds were freeze-dried for 24 hours (Freezone 4.5 by Labconco, USA) to eliminate the water and subsequently sintered.

\subsection{Rheology.}

The flow behavior and viscoelastic fingerprints of SiC suspensions and emulsions were analyzed in a Discovery Hybrid Rheometer HR1 (TA Instruments). The measurements were carried out with a parallel plate ( $\varnothing=40$ $\mathrm{mm}$ ) and a solvent trap cover (to prevent evaporation) under steady sensing. Viscoelastic behavior and linear viscosity region (LVR) were evaluated with stress-controlled amplitude sweeps at frequencies of $0.1 \mathrm{~Hz}$. The selfassembly of BCS-functionalized particles was monitored by measuring the viscoelastic properties (G', G') over time, immediately after adding the $\mathrm{pH}$ trigger. The oscillation measurements (time sweep with fixed frequency, 0.1 $\mathrm{Hz}$ and strain, $\gamma=1 \%$ ) were performed immediately after. The solvent trap cover prevented evaporation of the solvent, while the axial force control identified changes in volume and adjusted the gap automatically. 


\subsection{Sintering.}

Prior to sintering, debinding was carried out by heating the structures at 2 to 6 ${ }^{\circ} \mathrm{C} / \mathrm{min}$ up to temperatures ranging between 500 to $600{ }^{\circ} \mathrm{C}$ for $2 \mathrm{~h}$ (BCS burns at $500{ }^{\circ} \mathrm{C}$ according to the thermo gravimetric analysis). The macroporous scaffolds obtained with these two wet-processing approaches were sintered using Spark Plasma Sintering (SPS) and a conventional graphite furnace at temperatures ranging between $1800{ }^{\circ} \mathrm{C}$ and $2200{ }^{\circ} \mathrm{C}$. SPS was carried under vacuum for 8 minutes at the maximum temperature. The heating and cooling rates were $200{ }^{\circ} \mathrm{C} / \mathrm{min}$ and $150{ }^{\circ} \mathrm{C} / \mathrm{min}$ respectively. In the conventional graphite furnace, the scaffolds were fired in an inert atmosphere (Ar) with a heating and cooling rate of $20{ }^{\circ} \mathrm{C} / \mathrm{min}$. In selected liquid phase sintering experiments, the porous scaffolds were placed in a closed cylindrical crucible (50 $\mathrm{mm}$ in diameter and $60 \mathrm{~mm}$ in height) on top of a powder bed to enhance wall densification $[18,19]$. The weight of the powder bed was fixed at 5 times the weight of the green body.

\subsection{Characterization.}

The microstructure of the materials was analysed via scanning electron microscopy (SEM, Leo Gemini 1525). The Archimedes method (Sartorius, YDK01, Goettingen, Germany) was used to determine their density and porosity. Phase composition was determined by xRay diffraction (PANanalytical, Almelo, Netherlands) and Transmission electron microscopy (FEI $\operatorname{Titan}^{\mathrm{TM}}$ 80-300 operated at 300kV equipped with a field emission electron gun and a Cs-image corrector). TEM foils were prepared by focus ion beam (FIB) milling using a Helios NanoLab 600 instrument $\left(2-30 \mathrm{KeV} \mathrm{Ga}^{+}\right.$incident beam 
energy with current of $16 \mathrm{pA}-21 \mathrm{nA})$. xRay scan data were collected with Cua $(\lambda=1.54178 \AA)$ radiation at a step size of $0.1^{\circ}$ and 150 s for step. TEM was used to analyse the microstructure of LPS samples; high angle annular dark field (HAADF) scanning transmission electron microscopy (STEM) and Energy-dispersive X-ray spectroscopy (EDX) were employed to identify different phases within the microstructure.

Compression and bending tests were performed on a universal testing machine (Zwick/Roell 1474). Compression tests were done following the ASTM C133 [20] standard with a crosshead speed of $1.3 \mathrm{~mm} / \mathrm{min}$. In order to homogeneously distribute the load during compression, a stainless steel semi sphere was placed at the top of the samples. The 4-point bending tests were performed at a crosshead speed between 0.5 and $2 \mathrm{~mm} / \mathrm{min}$. For each material, 10 to 20 specimens measuring approximately $5 \times 5 \times 5 \mathrm{~mm}^{3}$ (for compression) and $4 \times 4 \times 20 \mathrm{~mm}^{3}$ (for bending) were cut from a ceramic part with a diamond disk and grinded to ensure parallel surfaces.

The thermal properties of the samples were measured using a Nezstch LFA 427 - Laser Flash Apparatus, at temperatures between $30{ }^{\circ} \mathrm{C}$ and $1500{ }^{\circ} \mathrm{C}$. Rectangular specimens of $10 \times 10 \mathrm{~mm}$ with a thickness of $1 \mathrm{~mm}$ were employed. A short energy pulse heated up the bottom surface of the sample, while the temperature on the upper surface was measured and monitored with an infrared detector. In some cases the specimens were coated with a graphite emulsion to help increase the energy absorbed on the laser side and the temperature signal at the detector. The thermal diffusivity was measured in argon atmosphere, using a heating rate of $10{ }^{\circ} \mathrm{C} / \mathrm{min}$. Between 3 and 5 measurements for each temperature were carried out. The "Cowan+pulse 
correction" diffusivity model was used for the processing of the experimental data. The thermal conductivities were calculated with Proteus $₫$ Software, using the acquired data of thermal diffusivity, specific heat and density of the samples. The variation of the specific heat of SiC with temperature $(\mathrm{T})$ was calculated as (temperature in K) [21]:

$$
C_{p}=1.267+0.049 \cdot 10^{-3} T-1.227 \cdot 10^{5} T^{-2}+0.205 \cdot 10^{8} T^{-3}
$$

\section{RESULTS}

\subsection{Processing of porous structures}

Direct assembly. BCS attachment to the SiC surfaces was evaluated by comparing the UV-visible absorbance at the excitation wavelength for rhodamine (566 nm, Fig. 1a). The results indicated that the BCS molecules interact with the particle surfaces, and also that the amount of BCS attached to the surface depends on the initial (c) and equilibrium ( $\left.c_{e q}\right)$ concentrations (Fig. 1b, c). The adsorption data can be described by a Langmuir isotherm (Fig. 1c). From this fitting, the maximum amount adsorbed $\left(\Gamma_{\max }\right)$ is 0.124 $\mathrm{mg} / \mathrm{m}^{2}$ (Fig. 1c). 


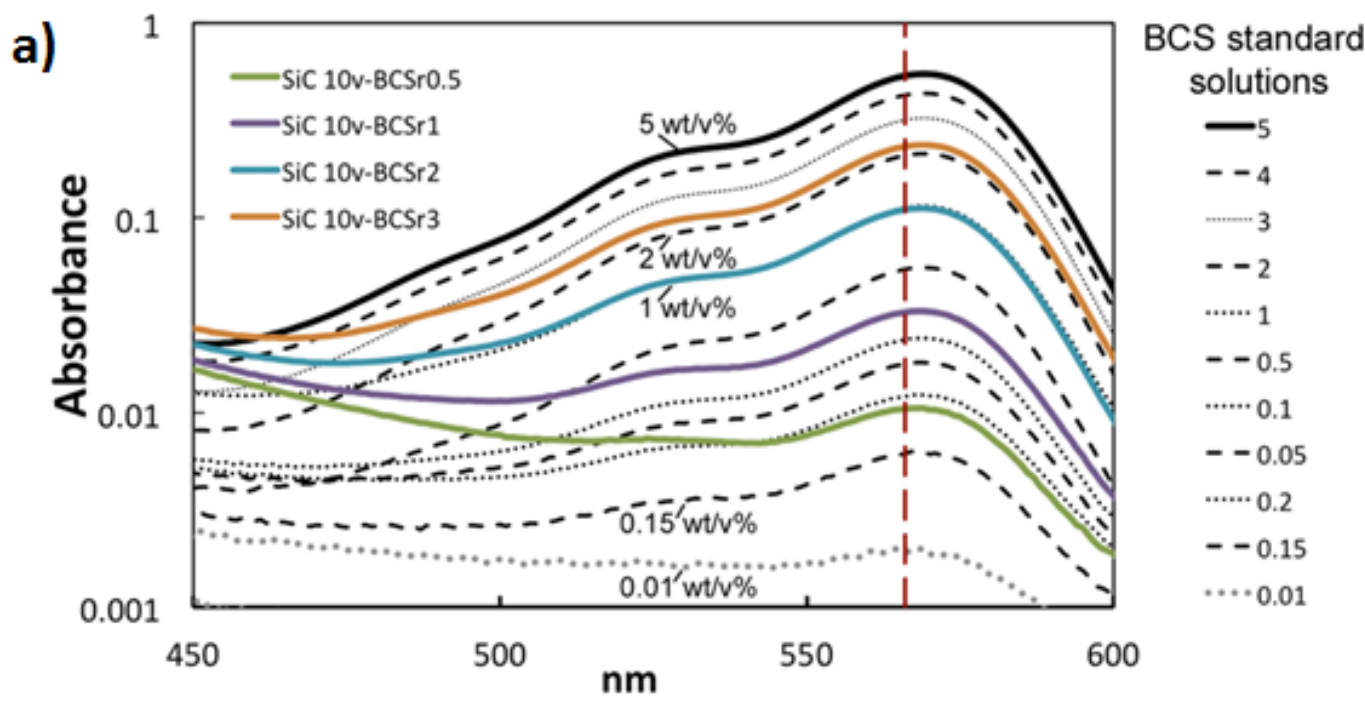

b)
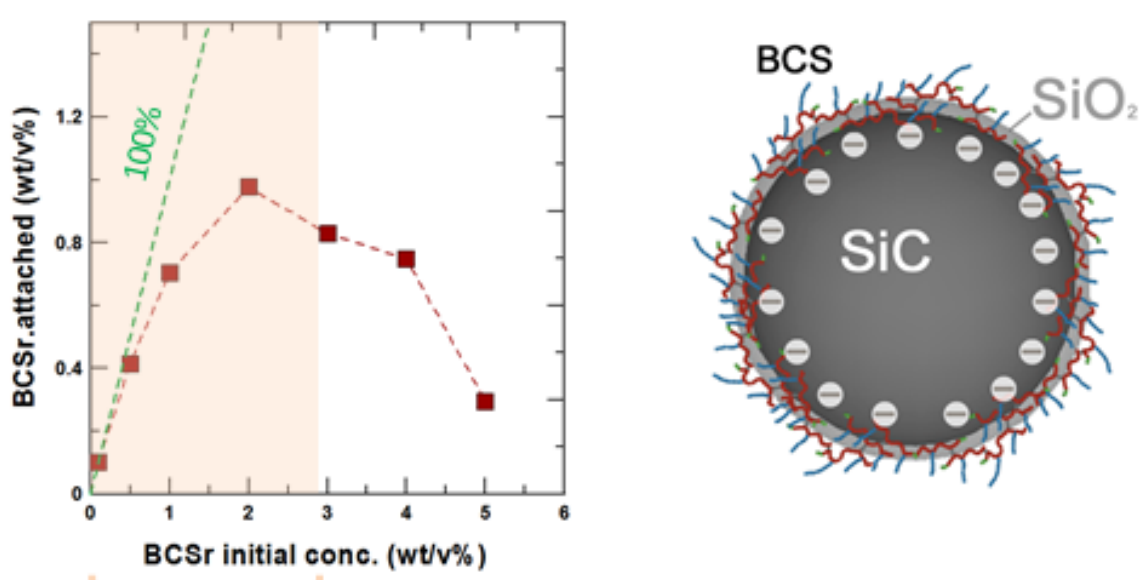

c)
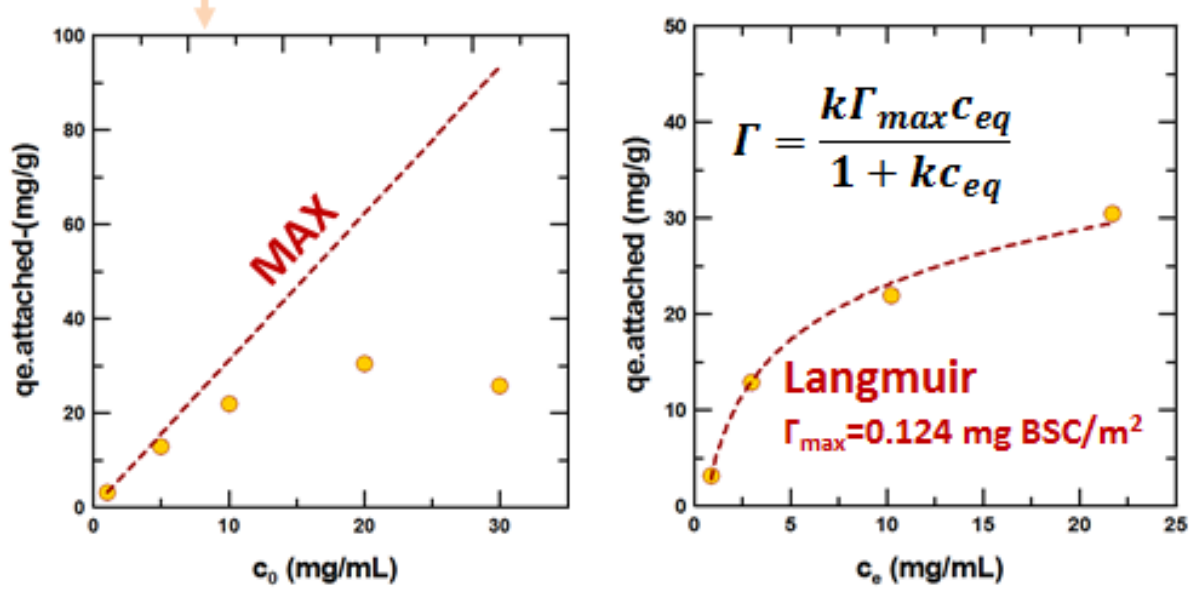

(In Color) Fig. 1 SiC surface functionalization Adsorption behavior of (rhodamine modified) branched copolymer surfactant on silicon carbide particles at pH 8-9. a) Graph showing the UV-visible spectra for BCS standard 
solutions (black lines) and the supernatants of SiC/BCS solutions with concentrations ranging from 0.5 to $3 w t / v \%$. All curves show the excitation peak for rhodamine at 566nm. There is a direct correlation between the intensity of this peak and the concentration of BCS in standard solutions and supernatants, allowing us to quantify the BCS/SiC adsorption isotherm. b) Attachment vs. initial BCS concentration, initially nearly the $100 \%$ of the molecules are attached, but at concentrations above $3 w t / v \%$ the amount of molecules adsorbed on SiC surface drops. c) The adsorption behaviour at concentrations below $3 w t / v \%$ follows the Langmuir model. The Langmuir isotherm equation and fitting parameters used to describe the amphiphilic adsorption behavior are shown as an inset in (c). Data were obtained for 10 vol \% silicon carbide suspensions.

SiC/BCS suspensions and emulsions show a strong shear thinning behavior and viscoelastic properties (Fig. 2a, b). The maximum solid loading for BCS stabilized SiC suspensions was 33.5 vol\%. These suspensions exhibit viscosities up to $183 \mathrm{~Pa}$.s at a shear rate of $0.004 \mathrm{~s}^{-1}$ (Fig. 2a). An almost identical behavior was observed for the emulsions. An amplitude sweep at 0.1 $\mathrm{Hz}$ showed that suspensions and emulsions exhibit a linear and predominantly elastic (G'>G') behavior at strains below $1 \%$, and their structure is broken down at higher strains leading to a non-linear and liquidlike behavior (G">G') (Fig. 2b). Despite the similarities in rheological behavior between the suspensions and the emulsions, it is also noticeable how the 
storage and loss moduli have similar values for the emulsified suspension, while G" is well below G' for the suspension at low strains (Fig. 2b).

Foam-like SiC structures were prepared by lowering the $\mathrm{pH}$ of the BCS-SiC emulsified suspensions, with of GoL. The hydrolysis of this sugar to gluconic acid homogeneously dropped the $\mathrm{pH}$ throughout the emulsion and activated multiple hydrogen bonds between the functionalities on the BCS branches (EG and MA). These non-covalent interactions directed the assembly of BCSfunctionalized $\mathrm{SiC}$ particles into a very well organized network through the continuous phase and O/W interface (Fig. 2d). This network forms a soft solid. By measuring the change in the viscoelastic properties with time, we could follow the assembly process (Fig. 2c). The starting SiC-BCS suspensions (at $\mathrm{pH} 8$ ) show a liquid-like behavior $\left(\mathrm{G}^{\prime \prime}>\mathrm{G}^{\prime}\right)$, within ten minutes after triggering the $\mathrm{pH}$ drop both moduli increase and reach the cross-over point ( $G^{\prime}=G^{\prime \prime}$, at this point the $\mathrm{pH}$ is less than 4, Fig. 2c). After that, both moduli keep rising at a similar rate up to values above $100 \mathrm{MPa}$. Emulsified $\mathrm{SiC}$ suspensions show certain elastic behavior prior assembly for the higher SiC and BCS concentrations. During the assembly process for emulsified suspensions, the crossover point was not detected; both moduli exhibit higher initial values (>10 Pa) and rapidly increase at initially fast rate up to values close to 100 MPa (Fig. 2c). After that, both moduli keep increasing but a slower pace and with unstable trend as a consequence of noise in the sinusoidal signal. The rheological studies indicated that establishing a network within the emulsion took 0.5 to 2 hours. 

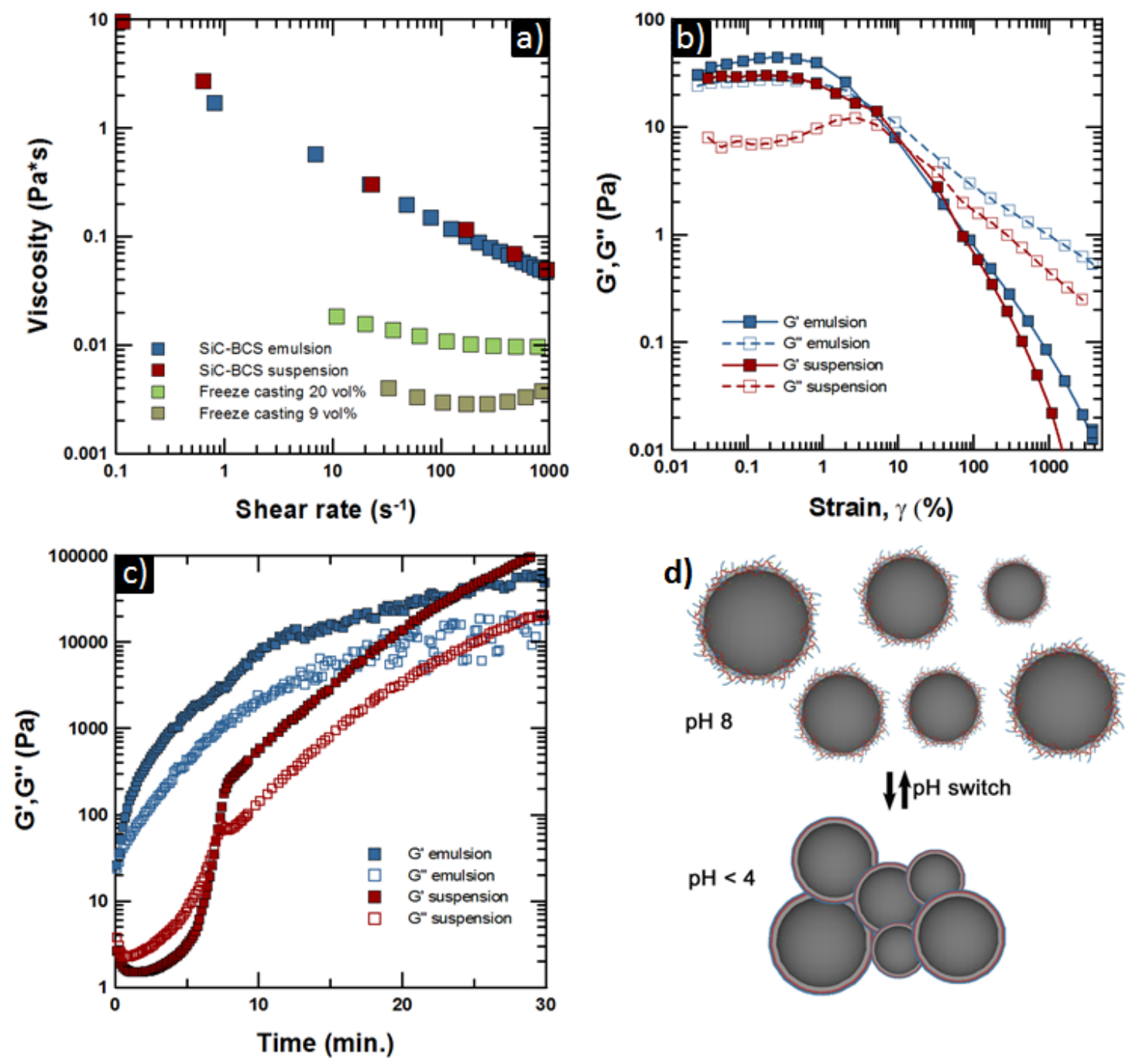

(In Color) Fig. 2 Rheological behaviour of SiC suspensions. a) The viscosity vs. shear rate graph shows that freeze casting suspensions are nearly Newtonian (SiC-FC), while SiC-BCS suspensions and emulsions for directed assembly are shear thinning. b) Viscoelastic fingerprints (storage (G') and loss (G") modulus) vs. strain for the BCS-SiC suspensions and emulsions. Both of them show a linear viscosity region below $2 \%$ strain and break down at higher strains. The suspension has a liquid-like behaviour (G">G') while the emulsion shows solid-like behaviour (G'>G') before triggering the assembly. c) Graph comparing the self-assembly kinetics for a SiC-BCS suspension and emulsion when the $\mathrm{pH}$ drops from 8 to $\mathrm{pH}<4$. The kinetics for the suspension shows that it initially has a liquid-like behaviour (G">G'), afterwards the 
magnitude of both modulus gradually increases and reach the cross over point $\left(G^{\prime}=G^{\prime \prime}\right)$ at approximately 8 mins. At this point the particle network is established. Both moduli keep increasing due to further activation of hydrogen bonds, making the particle network stronger. The kinetics for the emulsion follows the same trend, but in this case it is not possible to identify the crossover due to the predominantly elastic behaviour of the emulsion. d) Scheme illustrating the directed assembly depending on the $\mathrm{pH}$.

Once the emulsions were dried, the assembled particle networks exhibited very well organized foam-like architectures (Fig. 3b). Starting from SiC suspensions containing 33.5 vol\% particles stabilized with $1 \mathrm{wt} / \mathrm{v} \%$ of $\mathrm{BCS}$ and emulsified with 50 vol\% decane led to foam-like structures with spherical shaped cells, interconnected by micro openings between them (Fig. 3b). These foam-like structures have an apparent relative density of $0.19 \pm 0.04$ and pore sizes ranging from $\sim 10$ to $150 \mu \mathrm{m}$ before sintering (Fig. $3 b$ ). The microscopic SiC particles have a wide particle size distribution but also a faceted shape that did not facilitate packing and led to a high wall porosity (Fig. 3d). Alternatively, when using a mixed particle SiC suspension we obtained porous materials with a broader range of microstructures, with pore sizes below $10 \mu \mathrm{m}$, and green relative densities between 0.14 and 0.3 . Mixing of micro and nano nanoparticles improved packing in the walls (Fig. 4 a,b).

Freeze Casting. SiC suspensions prepared for freeze casting exhibited very different rheological behavior compared to the BCS-stabilized ones. For this technique, well-dispersed and stable suspensions with low viscosity are 
necessary to facilitate ice growth and avoid sedimentation. SiC suspensions with concentrations of 9 and 20 vol\% stabilized with TMAH exhibited nearly Newtonian behavior with very low apparent yield stress $(<0.2 \mathrm{~Pa}$ for both cases) and viscosities of 0.003 and $0.012 \mathrm{~Pa} \cdot \mathrm{s}\left(\right.$ at $100 \mathrm{~s}^{-1}$ ) respectively (Fig. 1a). Both suspensions were stable (negligible sedimentation) for 1 hour but some sedimentation occurred after 1 day, especially for the low concentrated ones.

Freeze casting of $\mathrm{SiC}$ suspensions generated lamellar structures. The walls are highly interconnected by thin bridges and have a characteristic surface roughness (Fig. 3a). The freezing rate is directly related to the speed of the advancing ice-front and the characteristics of the suspension (for example solid loading and thermal conductivity). A transparent mould made of Perspex was used to follow the ice-front tip growth in the 20 vol\% suspension [22]. The speeds of the freezing front varied between 13 and $27 \mu \mathrm{m} / \mathrm{s}$. The faster the freezing speed the finer is the microstructure in terms of lamellae thickness and pores width. The average lamella and pore sizes $\left(d_{50}\right)$ could be controlled from 30 to 9 and 37 to $12 \mu \mathrm{m}$, respectively. Higher speeds also provided a more homogeneous size distribution. For the sintering study, we have used green lamellar scaffolds with relative densities ranging from 0.1 to 0.2 , resulting from suspensions with 20 vol\% and 9 vol\% solid loading respectively. Although the nominal single particle $\mathrm{SiC}$ powder used had a wide particle size distribution their faceted shape did not facilitate optimum packing in the lamellae walls causing low green densities (Fig. 3c). As an alternative $\mathrm{SiC}$ suspensions with double particle size distributions were also freeze-casted. This provided better particle packing in the walls of the green 
structures. It also affected the freezing pattern. In freeze casted materials there are domains of lamella in different orientations in the plane perpendicular to the direction of ice growth. A bi-modal particle size distribution results in structures with smaller domains (Fig. 4 c,d).
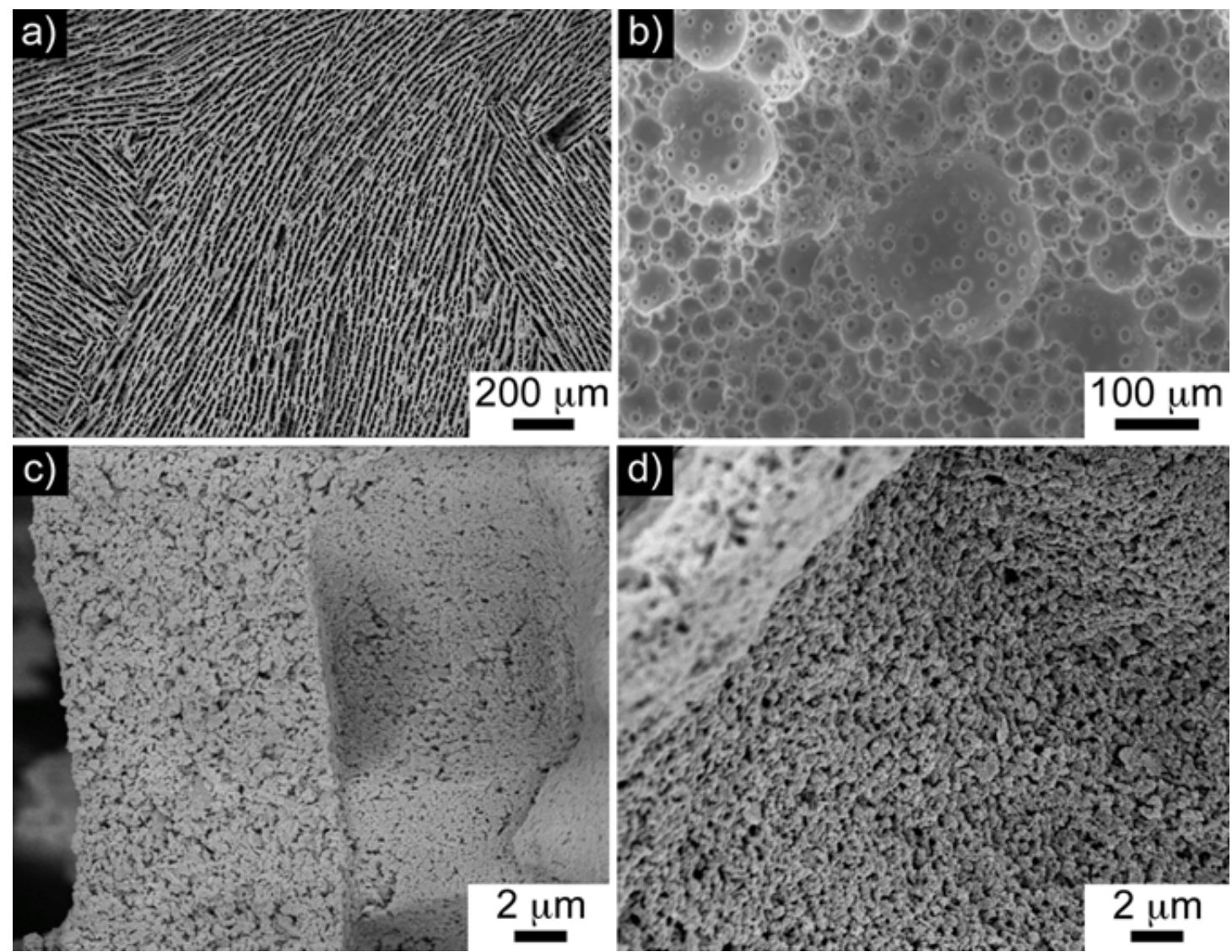

Fig. 3 SiC architectures before sintering obtained by freeze-casting (a) and directed assembly of responsive SiC emulsions (b). a) Freeze casted structures have lamellae aligned in domains and connected by bridges between them as a consequence of the ice templating process. b) Foam like structure obtained from the directed assembly of a suspension prepared with 33.5vol\% SiC particles, emulsified with 50vol\% decane. c) and d) details of the SiC particles in the walls of a lamellae (c) and foam (d). SiC particles 
show a faceted irregular shape that leads to the formation of voids between the particles.
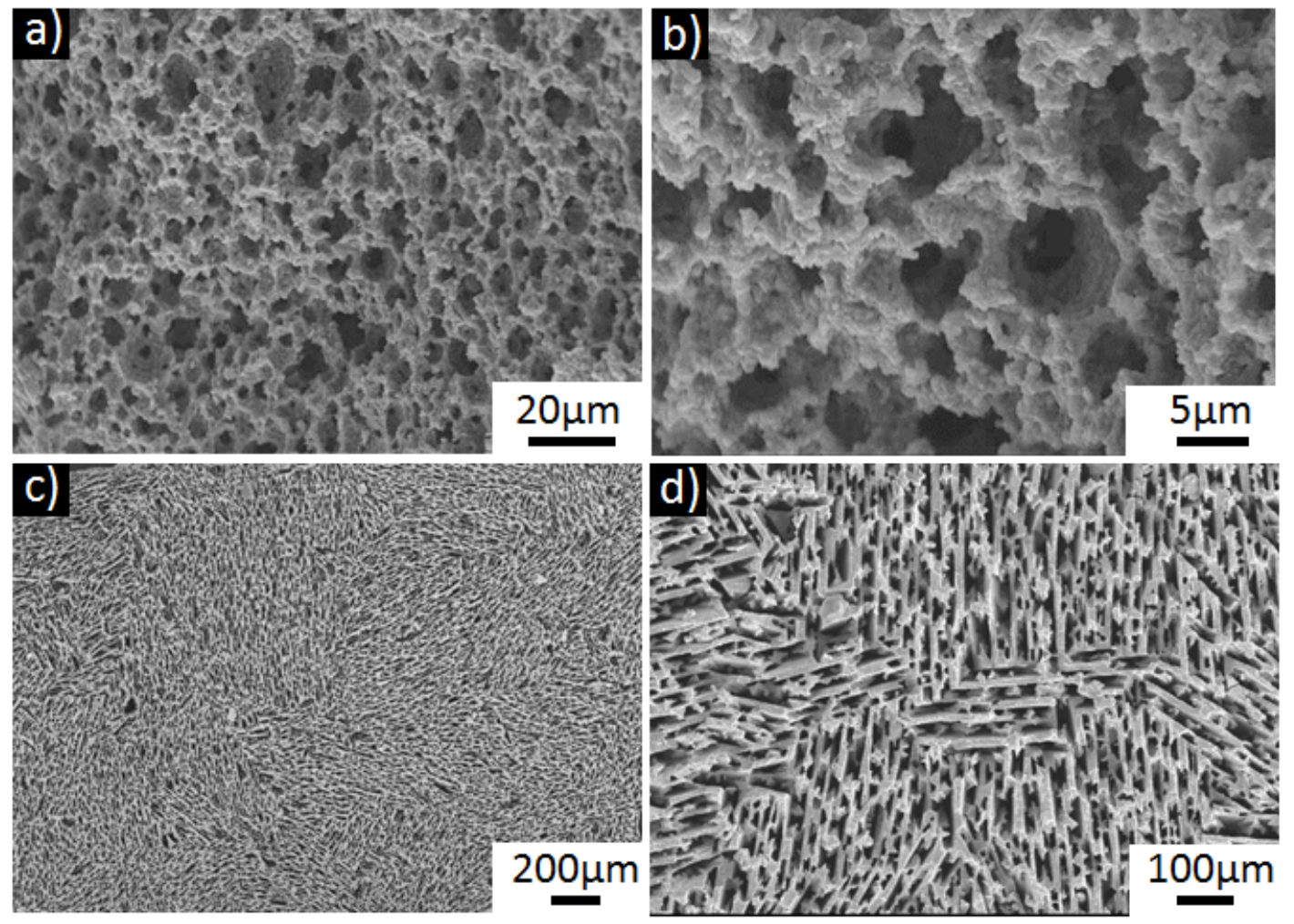

Fig. 4 SiC microstructures obtained using a bimodal particles size distribution with freeze casting and emulsion template approach. The pictures shown are of the samples after sintering. (a-b) Directed assembly of responsive SiC emulsions produce small and homogenously distributed pores, (b-c) Freeze casted structures show an high number of domains. 


\subsection{Sintering}

Wall densification was only achieved for samples that underwent liquid state sintering in a conventional furnace at $1800{ }^{\circ} \mathrm{C}$ for $2 \mathrm{~h}$, on top of a $\mathrm{SiC} / \mathrm{Al}_{2} \mathrm{O}_{3}$ powder bed (the powder bed contained $4 \mathrm{wt} \%$ of $\mathrm{Al}_{2} \mathrm{O}_{3}$ ) in a closed crucible. These samples retained the microscopic pore morphologies (Fig. 5). They exhibited good mechanical integrity and can be easily cut and polished. All the other cases (liquid state sintering or solid state in the conventional graphite or SPS furnaces, Fig. 6) resulted in very limited wall densification. The resulting materials have very low density $(\sim 0.20)$, and the pores are highly interconnected (up to $98 \%$ open pores). All the following results are for mechanical and thermal analyses performed on the scaffolds sintered using a liquid state sintering with a powder bed.
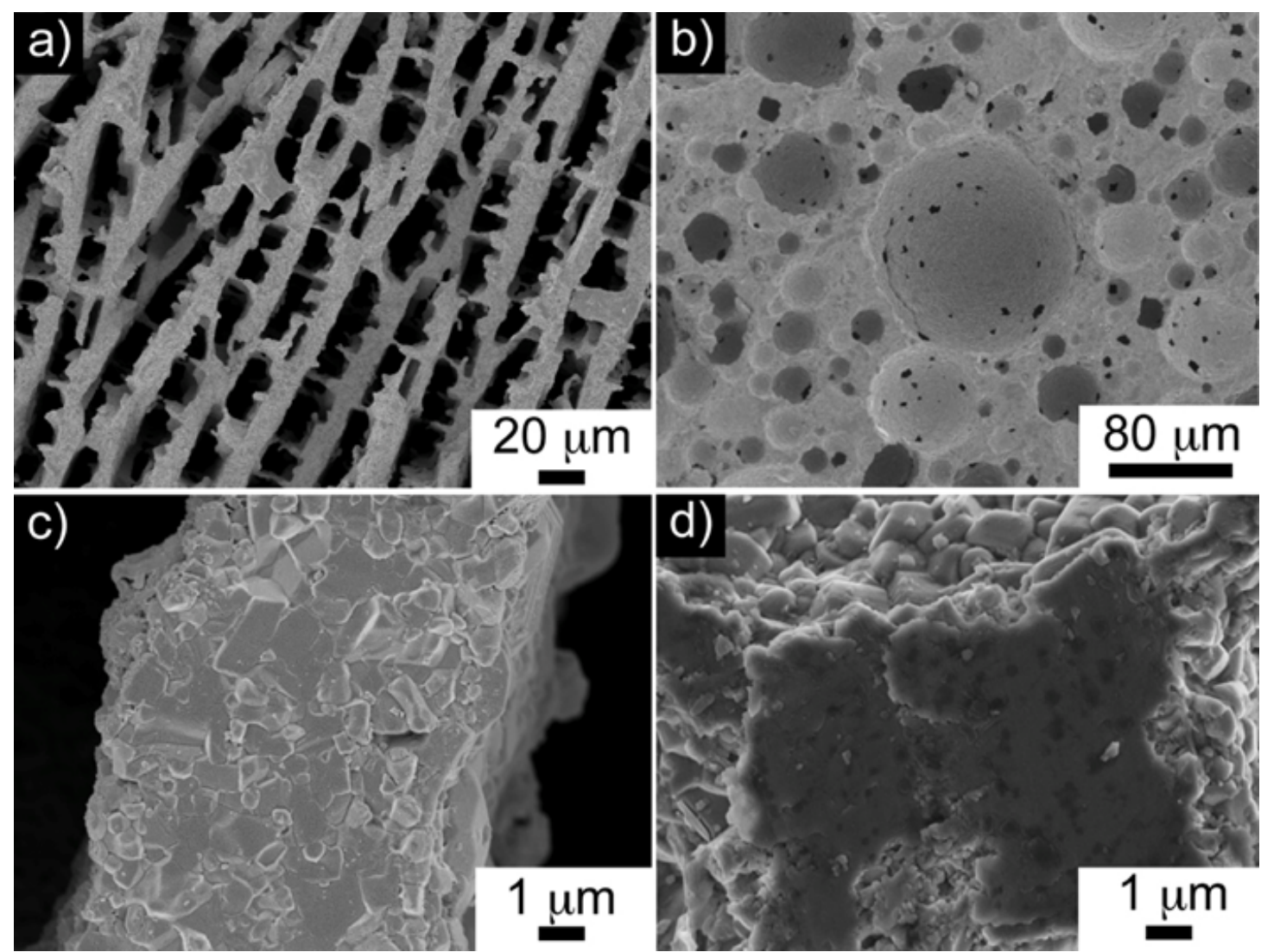
Fig. 5 SiC structures subjected to LS in conventional graphite furnace using a mix particles (SiC and Al2O3) sintering powder bed.
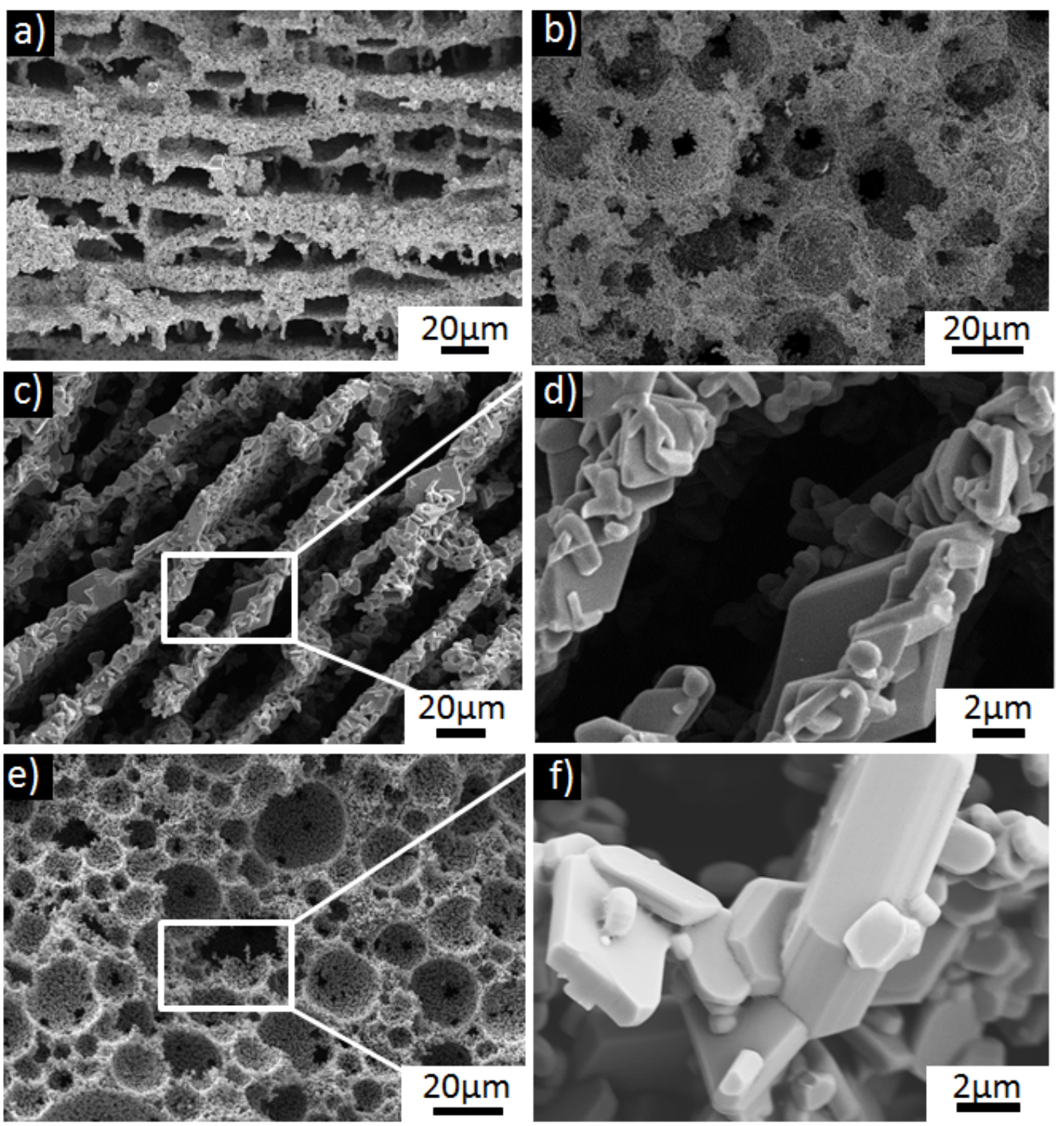

Fig. 6 SiC porous structures obtained by freeze casting and emulsion template sintered with a solid state (SS) approach (using Boron and Carbon as sintering aids) using a conventional graphite furnace and SPS.

Presureless SPS did not preserve the original architectures of the lamellar (a) and foam like (b) structures. The sintering was not homogenous throughout the samples, highly likely due to the fast heating rates that did not enable the 
formation of a uniform atmosphere within the samples. These conditions limited the grain growth but also to poor densification of the walls due to the high fraction of voids between grains.

c,e) SS in conventional graphite furnace. SS of the lamellar and foam-like structures led to poor consolidation and to exaggerated grain growth with platelet shape. a) In the freeze casted scaffolds, platelets were partially aligned in the lamellae. b) The lack of sintering between the platelets led to highly interconnected porosities (relative densities up to 0.18 with $76 \%$ open pores) and poor consolidation of the foams like structures. The highest densities obtained for SiC freeze casted and directed assembled scaffolds were 0.71 and $0.79 \mathrm{~g} / \mathrm{cm}^{3}$ respectively.

\subsection{Characterization.}

Structural. The porosity of foam-like structures was significantly reduced after sintering, final relative densities varied between 0.35 and 0.5 . Samples prepared using only one type of particles (with $d_{50} 450 \mathrm{~nm}$ ) exhibited an average isotropic shrinkage of $57 \pm 5 \%$ and final relative densities of $0.45 \pm$ 0.02 with open porosity ranging from 20 to $60 \%$, and pore sizes ranging from 5 to $120 \mu \mathrm{m}$. Foams prepared using mixed particle emulsions with 16 vol\% solids shrunk over $66 \%$ with final relative densities of 0.40 and open porosity up to $56 \%$.

Freeze casted scaffolds obtained from SiC suspensions with 9 vol\% solids, showed a final relative density of $\sim 0.25$ independent of the freezing rate. An increase of the solid loading up to 20 vol\% increased the density to $\sim 0.44$. 
Samples with 9 and 20 vol\% solid loading shrunk isotropically an average of $26 \%$ and $23 \%$ respectively in the freezing direction (related to the initial green dimensions). In all cases, faster freezing rates resulted in thinner lamellae and smaller pores (Table 2).

Table 2. Morphological features and mechanical properties of SiC scaffolds sintered at $1800^{\circ} \mathrm{C}$, for 2 hours in a conventional graphite furnace on a powder bed. All samples have been fabricated using one type of $\mathrm{SiC}$ particles $\left(d_{50} 450 \mathrm{~nm}\right)$

\begin{tabular}{|l|c|c|c|c|c|}
\hline & \multicolumn{4}{|c|}{ Freeze casting } & Emulsification \\
\hline Solid loading & \multicolumn{2}{|c|}{9 vol\% } & \multicolumn{2}{c|}{20 vol\% } & \\
\hline $\begin{array}{l}\text { Freezing rate } \\
(\mathrm{K} / \mathrm{min})\end{array}$ & 5 & 15 & 5 & 15 & \\
\hline $\begin{array}{l}\text { Lamellae } \\
\text { thickness } \\
(\mu \mathrm{m})\end{array}$ & $3.6 \pm 1.0$ & $3.1 \pm 0.8$ & $11.3 \pm 2.2$ & $9.3 \pm 1.4$ & \\
\hline $\begin{array}{l}\text { Pore size } \\
(\mu \mathrm{m})\end{array}$ & $15.5 \pm 4.9$ & $13.0 \pm 3.9$ & $14.9 \pm 2.6$ & $12.7 \pm 3.2$ & $30 \pm 20$ \\
\hline $\begin{array}{l}\text { Compressive } \\
\text { strength } \\
(\mathrm{MPa})\end{array}$ & $22 \pm 3$ & $33 \pm 6$ & $107 \pm 13$ & $135 \pm 23$ & $265 \pm 64$ \\
\hline $\begin{array}{l}\text { Flexural } \\
\text { strength } \\
(\mathrm{MPa})\end{array}$ & Dismissed & Dismissed & $40 \pm 16$ & $37 \pm 18$ & $33 \pm 5$ \\
\hline
\end{tabular}

Composition. For all samples, independently of the forming route, XRD analysis confirmed the evolution of the $\mathrm{SiC}$ crystalline structure from $6 \mathrm{H}$ to a mixture of $6 \mathrm{H}$ and $4 \mathrm{H}$ poly-types after sintering [4]. Secondary phases, such as $\mathrm{Al}_{5} \mathrm{Y}_{3} \mathrm{O}_{12}$ and $\mathrm{Al}_{2} \mathrm{O}_{3}$ were also identified (Fig. 7a). These results match the transmission electron microscopy observations. TEM images revealed different secondary phases (with a size of $100-600 \mathrm{~nm}$ and irregular shape) homogeneously distributed in between the SiC grains. Two different phases were identified by EDX: the first and more frequently found contains $\mathrm{Al}, \mathrm{Y}$ and $\mathrm{O}$ with an atomic ratio $\mathrm{Al} / \mathrm{Y} \sim 1.7$ (the brightest in the HADDF image, Fig. 7 $\mathrm{b}, \mathrm{c}$ ), and the second contains $\mathrm{Al}$ and $\mathrm{O}$ (with lower contrast in Fig. 7b). Microdiffraction patterns of the two phases confirmed that they are single crystalline 
$\mathrm{Al}_{5} \mathrm{Y}_{3} \mathrm{O}_{12}$ and $\mathrm{Al}_{2} \mathrm{O}_{3}$ respectively, in agreement with the $\mathrm{XRD}$ results. The grain boundaries between these secondary phases and SiC grains were clean and had an ordered structure, however glassy pockets rich in $\mathrm{Al}$ and $\mathrm{O}$ were found at some triple junctions (Fig. 7d). No thick equilibrium glassy film was found at the SiC grain bound but a small degree of disorder was observed. EDX analysis shows that these grain boundaries are rich in $\mathrm{Al}$ and $\mathrm{Y}$ but deficient in Si.
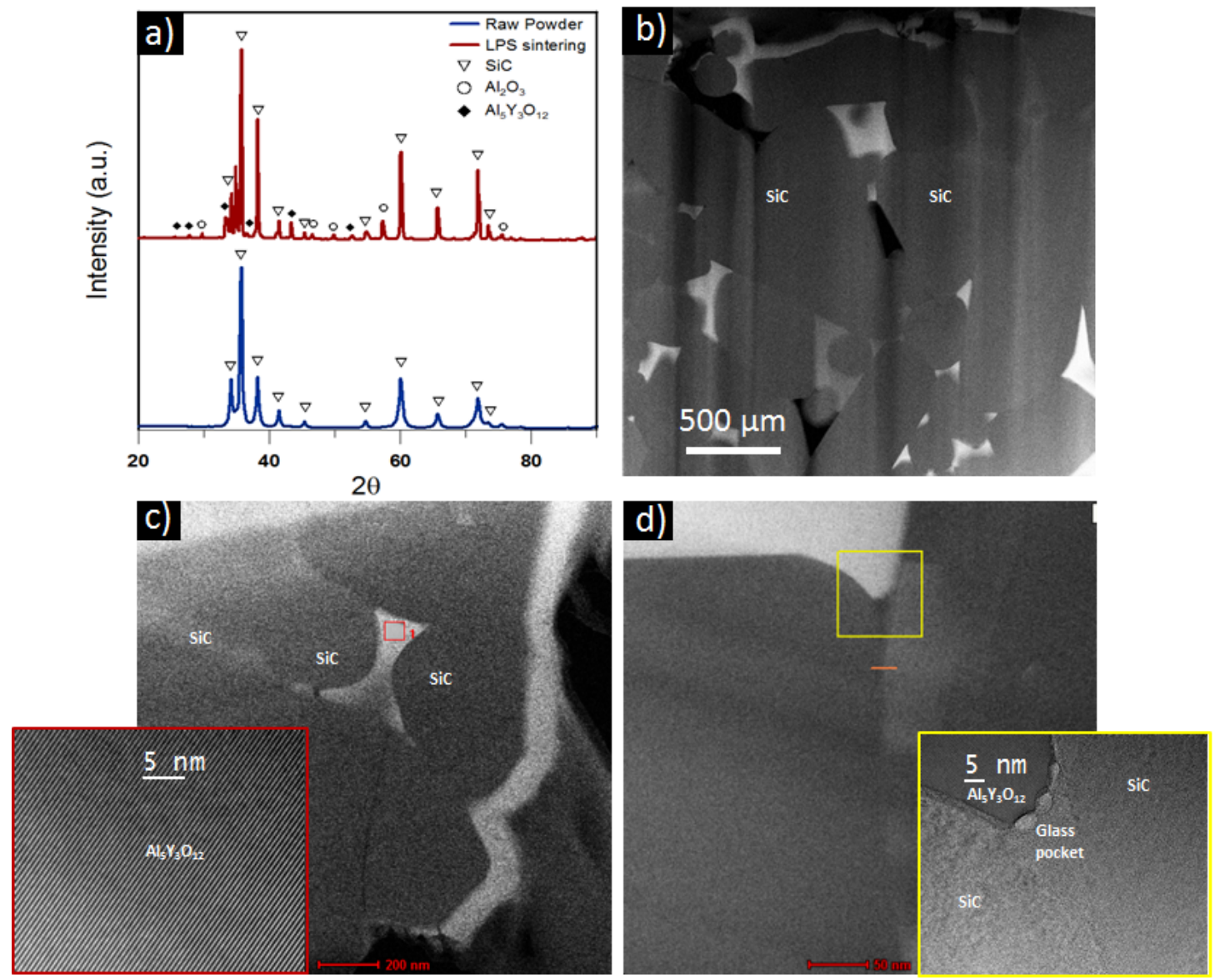

(In Colour) Fig. 7 TEM images of LPS silicon carbide using a sintering powder bed. a) X-ray spectrum of raw SiC powder and LPS. b,c) HRTEMHAADF images, where the darkest grains are SiC and the brighter phases are 
secondary phase; the brightest phase contains Al-Y-O, the less one only Al-O. The secondary phases present an ordered crystalline structure. d) Glass pocket at $\mathrm{SiC}$ and $\mathrm{Al}_{5} \mathrm{Y}_{3} \mathrm{O}_{12}$ triple junction.

Mechanical properties. Foam-like structures exhibit crushing strengths up to $350 \mathrm{MPa}$ (Table 2, Fig. 8a). Typical stress-strain compression curves have an initial linear elastic region where the stress quickly raises until a crushing event. A sudden decrease in stress takes place at strains above $10 \%$. After the initial critical crushing, the curves show a plateau where the foam with clear macroscopic cracks holds loads above $100 \mathrm{MPa}$ before densification. Stress-strain curves for the freeze casted materials show a different behavior. It was not possible to identify a critical crushing event for these structures; the stress initially increased with the strain until they reach a maximum and then gradually decreased without showing a clear crushing point. The structure did not fail catastrophically but a plateau region could be observed before densification (Fig. 8a).

Loading direction and processing conditions affected the crushing strength of freeze casted structures. Faster freezing rates (from 5 to $15 \mathrm{~K} / \mathrm{min}$ ) and higher solid contents led to higher strengths. Lamellar structures prepared from suspensions containing a mixed particle size distribution exhibited higher crushing strengths up to $280 \mathrm{MPa}$.

Despite the different behavior in compression, both types of structures have similar behaviors and strengths in flexural tests (Fig. 8c). Stress-strain curves show a short linear elastic region before critical fracture (Fig. 8c). The bending 
strengths follow the trend of similar materials found in literature (Table 2, Fig. 8d) [28]. Moreover, the bending strength of freeze casted structures does not significantly change with the processing conditions (for example freezing rate). In general, higher solid contents led to higher densities and as a consequence to an improvement of both, crushing and bending strengths. Flexural strengths for freeze casted scaffolds with low solid content (9 vol\%) and high porosity were dismissed. Due to their high porosity bending tests are not suitable for theses samples. The rods of the loading set-up made deep indentations in the samples from where cracks formed that led to failure.
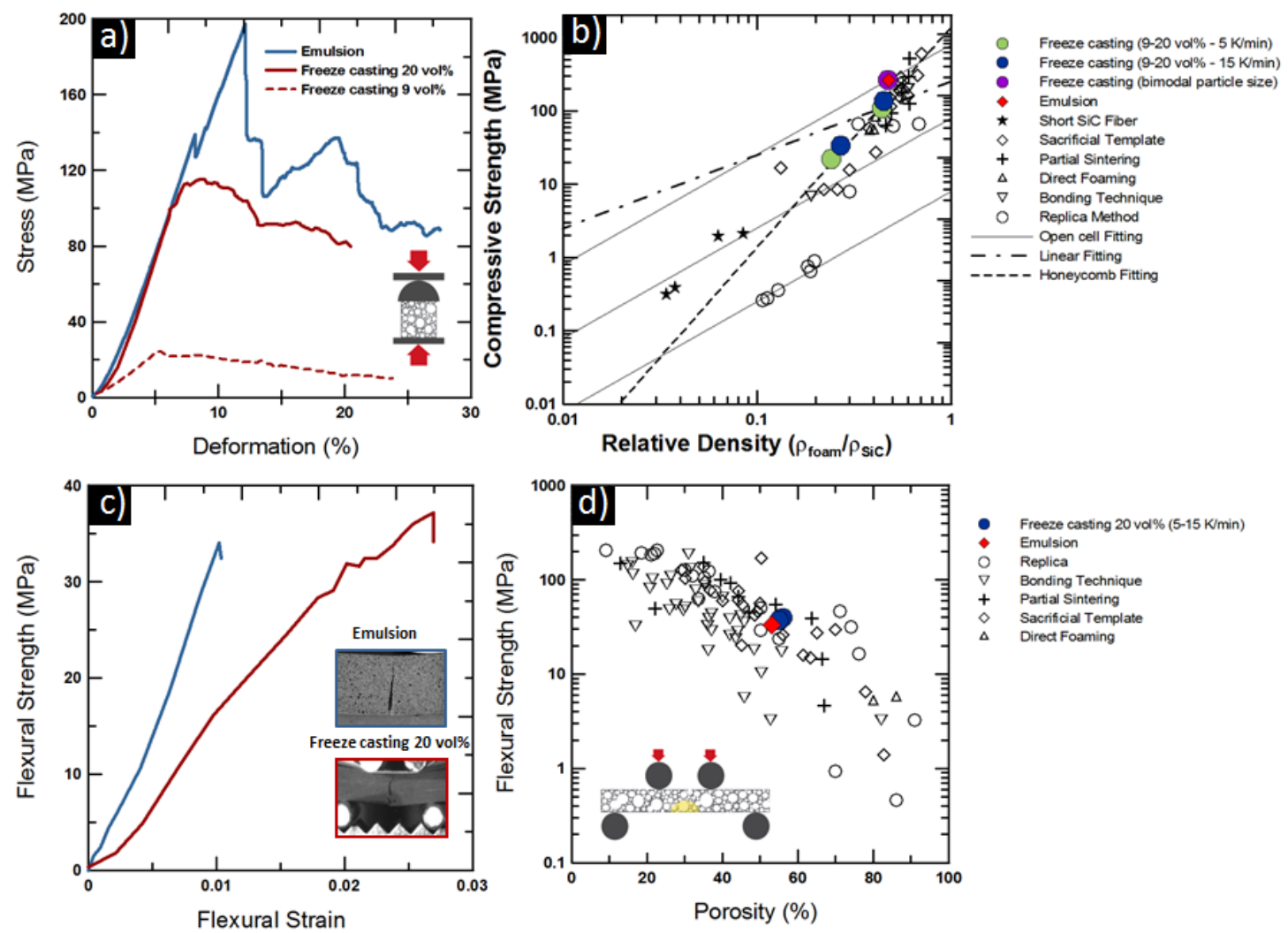

(In Colour) Fig 8. Mechanical characterization of freeze casted and emulsion templated SiC porous scaffolds sintered with LPS approach and sintering powder bed. a) Crushing strength of LPS freeze cast and emulsion templated 
SiC porous structures. The curves show the crushing resistance of the freeze cast scaffolds parallel to the freezing direction. b) Comparison of compressive strength vs. relative density of freeze cast and emulsion samples with other SiC macroporous scaffolds produced with different shaping techniques. In order to calculate the relative density a $\rho_{\text {Sic }}$ of $3.21 \mathrm{~g} / \mathrm{cm}^{3}$ has been considered. The fitting model for Open-cell foams in fracture dominated behaviour, for honeycombs loaded out of plane and for a linear fitting are reported. Different curves for the fracture dominated behaviour fitting are reported considering different strength $\left(\sigma_{\text {wall }}\right)$ of the SiC struts, from 40MPa up to $4 G P a$. c) Bending test curve in $4 P B$ of SiC porous bars. d) Comparison of flexural strength vs. porosity of freeze cast and emulsion templated SiC scaffolds and other SiC macroporous structures. Data from the literature comes from 3 and 4 point bending tests on samples with different sizes. This contributes to the scatter in the data and hampers comparison with theoretical models. Data taken from $[23,24]$

Thermal conductivity. The thermal conductivity of freeze casted scaffolds prepared with different solid loadings and freezing rates were measured along the two main anisotropic directions (parallel and perpendicular to the freezing direction). The isotropic foam-like scaffolds were measured in two random orientations (Fig. 9a). In general, thermal conductivity decreases with increasing porosity due to the gas trapped into the porous structures. A slight increase of thermal conductivity is observed when increasing the freezing rate. A significant decrease is observed when the thermal conductivity is measured perpendicular to the freezing direction, suggesting that pore 
morphology has a role on the final properties of the scaffolds. Self-assembled foam-like structures with a relative density of 0.51 have lower thermal conductivity values than freeze-casted scaffolds with lower relative densities of $\sim 0.44$ (Fig. 9a) with no significant variations along different directions.
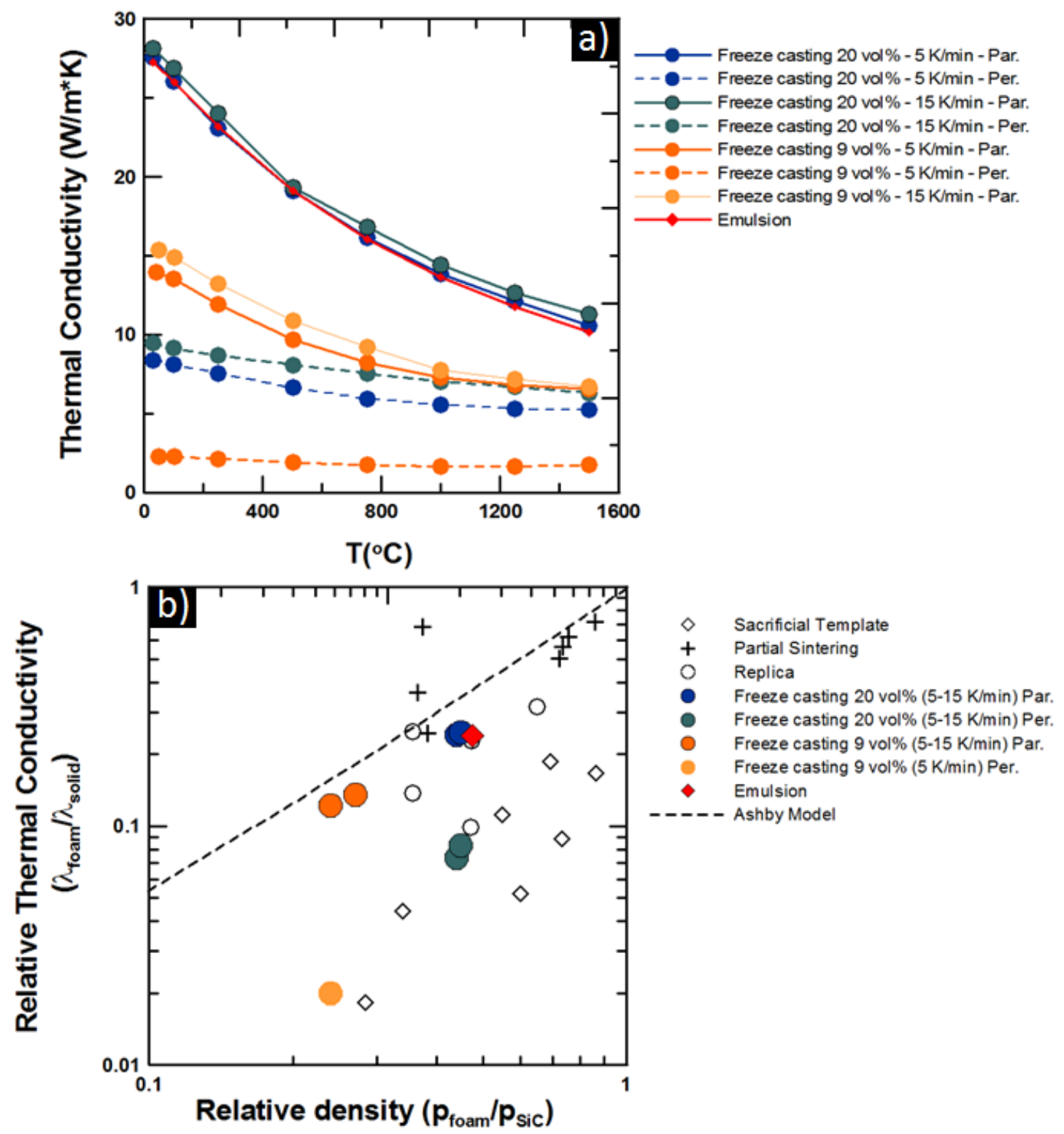

(In Colour) Fig. 9 Thermal conductivity of freeze cast and emulsion templated SiC porous structures sintered with LPS approach and sintering powder bed. a) Freeze cast scaffolds are analysed in the direction parallel and 
perpendicular to the freezing path. b) Thermal conductivity vs. porosity for the analysed scaffolds and other SiC macroporous scaffolds produced with different techniques. For the Ashby model a $\lambda_{s}$ of $114 \mathrm{~W} / \mathrm{m}^{*} \mathrm{~K}$ for SiC [25] and a $\lambda_{g}$ of $0.025 \mathrm{~W} / \mathrm{m}^{*} \mathrm{~K}$ for dry air at room temperature [26] have been considered. Data taken from [23].

\section{DISCUSSION}

The surface functionalization of $\mathrm{SiC}$ particles and oil droplets with BCS enables the controlled assembly of responsive $\mathrm{SiC}$ particles in the continuous phase and also at the interfaces of oil-in-water emulsified suspensions. This soft templating process combined with the versatility of the responsive ceramic particles provides an efficient approach to create SiC complex ceramics structures. The BCS molecules attach to SiC surfaces (Fig. 2) and their adsorption behavior can be described using a Langmuir isotherm (Fig. 2c). The fitting parameters provide the maximum amount of BCS that can be adsorbed onto the surface $\left(\Gamma_{\max }=0.124 \mathrm{mg} / \mathrm{m}^{2}\right)$, indicating that the surface of the particles in a suspension with a concentration of $10 \mathrm{vol} \%$ would be fully covered by using an initial concentration of BCS between 1 and $2 \mathrm{wt} / \mathrm{v} \%$. However, it is necessary to find a compromise between surface coverage, particle stabilization, functionalization, and rheological behavior while minimizing the amount of additive. We found that using an initial amount of 1 $\mathrm{wt} / \mathrm{v} \%$ (in the starting BCS solution) is enough for particle stabilization and functionalization. The interaction of BCS with the $\mathrm{SiC}$ surfaces may take place through a combination of mechanisms that differ slightly to other surface 
chemistries [14]. For alumina and graphene oxide we found a larger surface coverage of BCS $[14,27]$ with behaviors that deviate from Langmuir. The difference here is that the $\mathrm{SiC}$ surfaces are negatively charged at $\mathrm{pH} 8 . \mathrm{SiC}$ in water tends to oxidize to $\mathrm{SiO}_{2}$, which also has a negative surface charge at this $\mathrm{pH}$. The negative charges on $\mathrm{SiC} / \mathrm{SiO}_{2}$ surfaces at $\mathrm{pH}=8$, hamper the electrostatic attraction between the ionized MAA branches in the $\mathrm{BCS}\left(\mathrm{COO}^{-}\right.$ negatively charged) and the $\mathrm{SiC} / \mathrm{SiO}_{2}$ surfaces [28,29]. These electrostatic repulsions may lead to an open loop conformation of BCS on the adlayer, compared to the $\mathrm{BCS}$ arrangement at other surfaces (for example, $\mathrm{Al}_{2} \mathrm{O}_{3}$, or graphene oxide) where there are multiple attractive electrostatic interactions $[14,15,27]$. BCS has a very complex branched architecture, thus making difficult to predict and model the molecular conformation around the surfaces. However, due to these electrostatic repulsions, the BCS molecules may have fewer anchoring points to the $\mathrm{SiC} / \mathrm{SiO}_{2}$ surfaces, thus probably leading to the formation of more loops, and comb-like structures around the particle surfaces. This conformation is highly likely the responsible for the high viscosity of the suspensions and explains the predominantly elastic behavior in the emulsions (G'>G", Fig. 2). Possibly for the same reason, the maximum solid loading was limited to 33.5 vol\%, and even lower, only up to 16 vol\%, when preparing suspensions from mixed SiC particles.

These highly viscous suspensions can be easily emulsified with decane to obtain stable oil in water emulsions. The O/W interface is stabilized by the BCS molecules [17] and probably the functionalized SiC particles forming Pickering emulsions as it has been also observed for $\mathrm{Al}_{2} \mathrm{O}_{3}$ [14]. Particle size, shape and concentration play a very important role on interfacial stabilization 
and emulsification and therefore determine the microstructure of the material. For example, by using a suspension with mixed particles it is possible to emulsify suspensions with 16 vol\% solids to obtain very stable emulsions with smaller droplet size, thus reducing the apparent relative green density down to 0.14 and the final pore size below $10 \mu \mathrm{m}$ (Fig. 3b,d).

A controlled $\mathrm{pH}$ drop with $\mathrm{G} \delta \mathrm{L}$, triggers the assembly of a 3D particle network in the continuous phase and interfaces of these emulsions, thanks to the establishment of hydrogen bonds between the BCS molecules functionalizing the particles and oil-water interfaces. These molecular interactions are responsible for the establishment of a very well organized structure built from the nano to the macro scale [15]. The aggregation kinetics differs between suspensions and emulsions. For both, G' and G' values gradually increase immediately after triggering the $\mathrm{pH}$ due to the establishment of a particle network. There is an initial plateau, then a steep increase and a secondary plateau. Both moduli increase at a similar pace. The crossover point is just a relative parameter that indicates the transition from a liquid-like to a solid-like behavior that also depends on the conditions set during the measurement. The emulsified suspension shows a predominantly elastic behavior (G'>G") before triggering the assembly making and it is not possible to identify a crossover. They become stiffer after the $\mathrm{pH}$ drop due to the formation of a particle network. Consequently, the storage and loss modulus increase rapidly. The assembly process takes place within half an hour (Fig. 2c, d), and after a steep rising of G', G”, the quality of the signal decreases, what it might be related with the structure breaking down under the oscillating shear. At this stage, the particles can dis-assemble back into an emulsified suspension by 
raising the $\mathrm{pH}$, or the solvents can be evaporated in order to obtain a solid $3 \mathrm{D}$ architecture. By manipulating the processing conditions (i.e. solid loading, emulsification and assembly), we can tune the morphological features of the foam-like structures.

Stable and dispersed suspensions, with low viscosity, are needed to facilitate lamellar ice growth and avoid sedimentation during freeze casting. The rheological behavior of the SiC-TMAH suspensions, nearly Newtonian with low viscosity, was optimal for ice-templating, which took place always within 1 hour. The limited sedimentation observed in the less concentrated suspension was probably due to a lower steric stabilization. Using the description of Wegst et al. [30] of the sedimentation phenomena occurring within a colloidal suspension and considering a particle of silicon carbide in $0^{\circ} \mathrm{C}$ water it is possible to calculate that the maximum radius for laminar flow is $40.5 \mu \mathrm{m}$. The silicon carbide particles used in this study having a diameter of $0.4 \mu \mathrm{m}$ can be considered in laminar-flow and their sedimentation velocity can be estimated to be $\sim 0.43 \mu \mathrm{m} / \mathrm{s}$, which is relatively slow. Freeze casting enables certain level of microstructural control by manipulating the slurry concentration, freezing rate and additive formulation [31,32]. A decrease in solid loading leads to an increased porosity while the freezing rate determines the lamellae wavelength. As it has been previously observed with a range of materials, faster freezing speeds result in thinner lamellae and pores. At low freezing front speeds (below $20 \mu \mathrm{m} / \mathrm{s}$ ), minimal changes on the freezing speed significantly influence the final wavelength. As the freezing front speed increases the variation of the wavelength with the freezing rate slows down substantially and it seems difficult to reach wavelengths inferior to $\sim 20 \mu \mathrm{m}$ 
while using microscopic particles, as has been already reported in a previous study [10].

During sintering the challenge is to consolidate the SiC particles into a strong structure with dense walls, while preserving the porous architecture. Limited sintering results in poor cohesion and weak structures meanwhile large densification could reduce the desired porosity, making necessary to find a compromise between them. Different processing routes have been used to fabricate porous SiC structures with different range of porosities and pore sizes. The partial sintering method produce porous SiC with porosity below $65 \%$ and pore sizes going from 0.1 to $10 \mu \mathrm{m}$ [23]. This method usually requires low sintering temperatures to partially sinter coarse $\mathrm{SiC}$ particles producing uniformly distributed residual porosity. It does not require the use of sintering additives. The replica method allows the fabrication of highly porous scaffolds with porosity ranging from 60 up to $98 \%$ and cell size from $100 \mu \mathrm{m}$ up to millimeters providing limited microstructural control [23]. In this case the amount of additives and the sintering temperatures influence strongly the final porosity. Sacrificial template methods, as the ice-templating used in this study, use a template as pore forming agent that is subsequently removed during sintering. This technique allows good control over the porosity, pore size and pore morphology, producing porosities that can range from 15 up to $95 \%$ and pore sizes from 1 to $700 \mu \mathrm{m}$ [23]. Sintering conditions have to be properly tailored to preserve the microstructure imposed during processing. Alternative methods, to overcome the sinterability problems of $\mathrm{SiC}$, are the use of pre-ceramic polymer precursors or wood-derived carbon foams. The advantages of these processes are lower sintering temperature (1000- 
$1200^{\circ} \mathrm{C}$ ) and no need of sintering aids, but they also show some disadvantages. Wood derived scaffolds are strongly anisotropic [25] and often, residual carbon and silicon are generated [33]. The use of pre-ceramic polymer precursors leads to large shrinkage during the conversion that produces defects and cracks within the foams [7]; increasing the firing temperature at which the polymer is converted into ceramic increases shrinkage. Finally, in both cases the processes needed to achieve the final products are extremely complex and involve many different steps. In this study two different sintering routes were considered, solid and liquid phase sintering. Solid state sintering always led to exaggerated grain growth with the formation of large SiC platelets and poor wall densification (Fig. 6 c, d, e, f). Scaffolds sintered in the SPS showed heterogeneities and multiple cracking. The high speed of the SPS process combined with the low thermal conductivity of the porous structures can results in inhomogeneous temperature distribution. The process is not appropriate for the sintering of delicate porous structures (Fig. 6 a, b). Another factor that hampers densification is poor packing of the faceted and irregularly shaped SiC particles (Fig. 3c, d).

Liquid state sintering, with large amount of additives (up to $20 \mathrm{wt} \%$ ), has been previously used to consolidate porous SiC structures [10]. In this work we are able to improve the wall densification and preserve the porous architectures, by combining liquid phase sintering (with reduced amount of additives) with a controlled atmosphere that prevents evaporation. The liquid phase formed at high temperature promotes sintering thus increasing the density of the walls. By placing the samples on top of a $\mathrm{SiC} / \mathrm{Al}_{2} \mathrm{O}_{3}$ powder bed, it is possible to 
create a controlled atmosphere at high temperature. The powder bed in a closed crucible generates volatile metal sub-oxides with sufficient partial pressure to prevent, or limit the evaporation of the sintering aids, and therefore enhance densification $[18,19]$. Optimal wall densification is achieved when the powder bed contains 4 wt $\%$ of $\mathrm{Al}_{2} \mathrm{O}_{3}$ (Fig. 5). Both, lamellar and foam-like structures show good wall densification and also preserve the original microstructure (Fig. 5). Under these conditions liquid sintering also implies considerable shrinkage. As expected the additives react to form crystalline $\mathrm{Al}_{5} \mathrm{Y}_{3} \mathrm{O}_{12}$ and $\mathrm{Al}_{2} \mathrm{O}_{3}$ (Fig. 7)[4,34].

The different structures resulted in different qualitative stress/strain response under compression. In the foams, critical fracture events that result in a clear stress reduction can be identified followed by a plateau. This is a characteristic behavior for brittle foams where the drops in strength correspond to the fracture of cell walls. In layered materials the decrease in strength (compression in the direction parallel to the ice growth direction) is more gradual. It has been proposed that the layered materials fail by buckling. Gradual failure could result from the consecutive failure of individual layers. Foams seem to reach much larger compressive strengths. It was possible to reach higher compressive strengths in the freeze casted materials (comparable to foams) by using double particle size distributions. The reason can be double: better particle packing and wall densification and a change towards a more isotropic structure where the lamellae domains are smaller and the walls more interconnected. 
Different models can be used to analyse the experimental data (Fig. 8b). According to these models, the following equations can be used to predict the strength of the porous material, $\sigma_{\text {foam }}$ [35]:

$$
\begin{array}{ll}
\sigma_{\text {foam }}=0.2 \sigma_{\text {wall }}\left(\frac{\rho_{\text {foam }}}{\rho_{\text {wall }}}\right)^{\frac{3}{2}} \quad \text { Open-cell in fracture dominated behaviour } \\
\sigma_{\text {foam }}=6 E_{\text {wall }}\left(\frac{\rho_{\text {foam }}}{\rho_{\text {wall }}}\right)^{3} & \text { Honeycomb loaded out-of plane } \\
\sigma_{\text {foam }}=\sigma_{\text {wall }}\left(\frac{\rho_{\text {foam }}}{\rho_{\text {wall }}}\right) & \text { Linear }
\end{array}
$$

were $\sigma_{\text {wall }}$ is the strength of the walls, $E_{\text {wall }}$ their Young Modulus and $\rho_{\text {foam }}$ and $\rho_{\text {wall }}$ the density of the foam and the walls respectively.

The freeze cast and emulsion samples produced in this study are in upper limit in terms of crushing strength compared with samples with similar density obtained with different shaping technologies (Fig. 8b). As the relative density of the scaffolds increases above 0.1 , the honeycomb model fits better the experimental data.

Fitting to the honeycomb model that fits best the freeze cast scaffolds an elastic modulus of $E_{\text {wall }}=230 \mathrm{MPa}$ is obtained [36]. This elastic modulus is three orders of magnitude lower than the value for dense SiC ( 400GPa [37]). A lower modulus could be explained by incomplete densification of the lamellae walls. The morphology of the SiC freeze casted scaffolds can be also closely modelled as parallel plates loaded in compression rather than proper honeycombs. Considering buckling as the dominant failure mode for freeze casted structures [38] and applying the equation for Euler buckling, [39]: 


$$
F=\frac{\pi^{2} E_{\text {wall }} I}{(K L)^{2}}
$$

where $F$ is the force that will cause Buckling, $I$ the first momentum of inertia $\left(\boldsymbol{b} h^{3} / 13, \boldsymbol{b}\right.$ and $h$ the wall width and depth, 20 and $100 \mu \mathrm{m}$ respectively), $E_{\text {wall }}$ the elastic modulus of $\mathrm{SiC}(400 \mathrm{GPa}), K=1$ for a wall with hinged ends and $L$ is the length of the beam $(5 \mathrm{~mm})$. The expected strength $(\sigma=F /(b \cdot h))$ for a single lamellae failing due to buckling is $\sim 135 \mathrm{MPa}$. This value is similar to the experimental one obtained by compression, meaning that failure of freeze cast scaffolds could be caused by buckling.

Previous works on the mechanical behavior of alumina foams point towards bending tests as the best tool to quantitatively compare different porous materials as it is easier to identify a fracture point [40]. The bending strengths of the freeze casted structures in the stronger direction are very similar to those of foams and depend mostly on the density.

The thermal conductivities are of the order of those reported for porous SiC [23] suggesting again that density is the main factor. As expected from their architecture, materials fabricated by emulsification exhibit an isotropic response while freeze casted materials are highly anisotropic. They show higher thermal conductivity in the longitudinal direction (parallel to freezing rate), due to the heat transfer along the dense lamellae. The conductivity drops in the direction perpendicular to the freezing front. The differences between samples with same solid loading but obtained with different freezing conditions may be related to the number of lamellae per unit of transversal area. Samples frozen at higher freezing speed showed slightly higher thermal conductivity of those frozen at $5^{\circ} \mathrm{C} / \mathrm{min}$ for both solid contents. A decrease of 
the thermal conductivity is observed for all the samples when increasing the temperature up to $1500^{\circ} \mathrm{C}$ (Fig. 9a). As reported in a previous study [26] at high temperature, in highly porous ceramics, the radiative component of the thermal conductivity reaches significant values. Therefore the variation of the thermal conductivity with temperature depends strongly on the material and the structure. The contribution of gas convection to the thermal conductivity changes significantly less than the solid conduction components over a large range of temperatures [38], which can explain the very small variation of the thermal conductivity with the temperature in the perpendicular direction to the freezing rate. In the latter case, the contribution of the gas phase (entrapped between the ceramic lamellae) to the conductivity becomes more relevant. In all cases, thermal conductivity remains relatively stable up to high temperature making these scaffolds suitable for high temperature applications. Similar values of thermal conductivity can be found in literature for SiC macroporous scaffolds produced with different processing techniques [23]. Considering a simple model proposed by Ashby [35], where the thermal conductivity of a foam can be considered as the thermal conductivity through the solid walls and the air entrapped between the pores, the thermal conductivity can be calculated using the following equation:

$$
\frac{\lambda_{\text {foam }}}{\lambda_{s}}=\frac{\lambda_{g}}{\lambda_{s}}+\left(\frac{1}{3}-\frac{\lambda_{g}}{\lambda_{s}}\right)\left(\frac{\rho_{\text {foam }}}{\rho_{\text {wall }}}\right)+\frac{2}{3}\left(\frac{\rho_{\text {foam }}}{\rho_{\text {wall }}}\right)^{3 / 2}
$$

where $\lambda_{\text {foam }}$ is the thermal conductivity of the scaffold, $\lambda_{s}$ is the thermal conductivity of the bulk material and $\lambda_{g}$ is the thermal conductivity of the entrapped gas. Despite the fact the Ashby model is for isotropic foams, the thermal conductivity of the freeze casted scaffolds, in the direction parallel to the freezing direction, seems to follow a trend similar to the model predictions 
(Fig. 9b). The thermal conductivity in the direction perpendicular to the freezing direction decreases faster as the porosity increases compared to the model probably due to the less effective heat transfer within this configuration.

\section{CONCLUSION}

Porous SiC preforms have been fabricated through the directed assembly of responsive emulsions or by freeze casting. The resulting structures are very different. While emulsions can be used to fabricate isotropic foams, freeze casting results in highly oriented lamellar materials. Different processing variables (solid loading on the starting suspensions, particle size distribution, emulsification or freezing conditions) can be used to manipulate structure (porosities, pore sizes and shapes). After forming, liquid phase sintering in a controlled atmosphere is the best way to promote consolidation and the formation of dense ceramic walls in the structures. Our data show that there is a clear relationship between processing conditions, microstructure and mechanical properties and thermal conductivity. Strength seems to depend mostly on density although in freeze casted materials structures with smaller lamellar domains tend to be stronger. The values obtained in this work are in the upper limit of those reported for porous SiC with similar densities fabricated by other techniques. Thermal conductivities also depend mostly on density and are relatively stable up to $1500^{\circ} \mathrm{C}$ although the materials architecture also results in some differences. As expected, the conductivity of freeze casted materials is anisotropic and significantly lower in the direction perpendicular to the ceramic lamellae. 


\section{Acknowledgements}

The authors would like to acknowledge the European Commission funding under the 7th Framework Programme (Marie Curie Initial Training Networks; grant number: 289958, Bioceramics for Bone Repair) and the support of US Army Research, Development and Engineering Command Forward Element Command Atlantic, RFEC-ATL, Office of Naval Research Global, ONRG, and Defense Advanced Research Projects Agengy, DARPA. M.M. and S.B. would like to acknowledge the European Commission (FP7 Marie Curie IntraEuropean Fellowship, Biomimetic organic-inorganic hybrid structural materials, BIOHYMAT, and Advanced Composites Inspired by Nature, ACIN).

\section{References}

[1] M. Fukushima, M. Nakata, Y. Zhou, T. Ohji, Y. Yoshizawa, Fabrication and properties of ultra highly porous silicon carbide by the gelation-freezing method, J. Eur. Ceram. Soc. 30 (2010) 2889-2896. doi:10.1016/j.jeurceramsoc.2010.03.018.

[2] S. Prochazka, R.M. Scanlan, Effect of boron and carbon on sintering of SiC, J. Am. Ceram. Soc. 58 (1975) 72-72. doi:10.1111/j.11512916.1975.tb18990.x.

[3] H.N. Yoshimura, a. C. Da Cruz, Y. Zhou, H. Tanaka, Sintering of 6H( $\alpha)-\mathrm{SiC}$ and $3 \mathrm{C}(\beta)$-SiC powders with B4C and C additives, J. Mater. Sci. 37 (2002) 1541-1546. doi:10.1023/A:1014964701803.

[4] A. Gubernat, L. Stobierski, P. Łabaj, Microstructure and mechanical properties of silicon carbide pressureless sintered with oxide additives, J. Eur. Ceram. Soc. 27 (2007) 781-789. doi:10.1016/j.jeurceramsoc.2006.04.009.

[5] Y. Zhou, K. Hirao, M. Toriyama, H. Tanaka, Very Rapid Densification of Nanometer Silicon Carbide Powder by Pulse Electric Current Sintering, J. Am. Ceram. Soc. 83 (2000) 654-656. doi:10.1111/j.11512916.2000.tb01249.x.

[6] F. Lomello, G. Bonnefont, Y. Leconte, N. Herlin-Boime, G. Fantozzi, Processing of nano-SiC ceramics: Densification by SPS and mechanical characterization, J. Eur. Ceram. Soc. 32 (2012) 633-641. doi:10.1016/j.jeurceramsoc.2011.10.006. 
[7] M.R. Nangrejo, M.J. Edirisinghe, Porosity and strength of silicon carbide foams prepared using preceramic polymers, J. Porous Mater. 9 (2002) 131-140. doi:10.1023/A:1020834509443.

[8] B.-H. Yoon, C.-S. Park, H.-E. Kim, Y.-H. Koh, In Situ Synthesis of Porous Silicon Carbide (SiC) Ceramics Decorated with SiC Nanowires, J. Am. Ceram. Soc. 908 (2007) 3759-3766. doi:10.1111/j.15512916.2007.02037.x.

[9] S. Chabi, V.G. Rocha, E. García-Tuñón, C. Ferraro, E. Saiz, Y. Xia, Y. Zhu, Ultralight, Strong, Three-Dimensional SiC Structures, ACS Nano. 10 (2016) 1871-1876. doi:10.1021/acsnano.5b05533.

[10] V. Naglieri, H.A. Bale, B. Gludovatz, A.P. Tomsia, R.O. Ritchie, On the development of ice-templated silicon carbide scaffolds for nature-inspired structural materials, Acta Mater. 61 (2013) 6948-6957. doi:10.1016/j.actamat.2013.08.006.

[11] K. Cai, B. Román-Manso, J.E. Smay, J. Zhou, M.I. Osendi, M. Belmonte, P. Miranzo, Geometrically complex silicon carbide structures fabricated by robocasting, J. Am. Ceram. Soc. 95 (2012) 2660-2666. doi:10.1111/j.15512916.2012.05276.x.

[12] E. Munch, M.E. Launey, D.H. Alsem, E. Saiz, a P. Tomsia, R.O. Ritchie, Tough, bio-inspired hybrid materials., Science (80-. ). 322 (2008) 1516-1520. doi:10.1126/science.1164865.

[13] S. Deville, E. Saiz, A. P.Tomsia, Freeze casting of hydroxyapatite scaffolds for bone tissue engineering, Biomaterials. 27 (2006) 5480-5489. doi:10.1016/j.biomaterials.2006.06.028.

[14] E. García-Tuñon, G.C. Machado, M. Schneider, S. Barg, R. V. Bell, E. Saiz, Complex ceramic architectures by directed assembly of "responsive" particles, J. Eur. Ceram. Soc. 37 (2017) 199-211. doi:10.1016/j.jeurceramsoc.2016.06.050.

[15] E. Garcia-Tunon, S. Barg, R. Bell, J.V.M. Weaver, C. Walter, L. Goyos, E. Saiz, Designing Smart Particles for the Assembly of Complex Macroscopic Structures, Angew. Chemie Int. Ed. 52 (2013) 7805-7808. doi:10.1002/anie.201301636.

[16] V. Naglieri, B. Gludovatz, A.P. Tomsia, R.O. Ritchie, Developing strength and toughness in bio-inspired silicon carbide hybrid materials containing a compliant phase, Acta Mater. 98 (2015) 141-151. doi:10.1016/j.actamat.2015.07.022.

[17] R.T. Woodward, R. a Slater, S. Higgins, S.P. Rannard, A.I. Cooper, B.J.L. Royles, P.H. Findlay, J.V.M. Weaver, Controlling responsive emulsion properties via polymer design., Chem. Commun. (Camb). (2009) 35543556. doi:10.1039/b904320a.

[18] E.J. Winn, W.J. Clegg, Role of the Powder Bed in the Densification of Silicon Carbide Sintered with Yttria and Alumina Additives, J. Am. Ceram. Soc. 82 (1999) 3466-3470. doi:10.1111/j.1151-2916.1999.tb02266.x.

[19] V. V. Pujar, R.P. Jensen, N.P. Padture, Densification of liquid-phase-sintered silicon carbide, J. Mater. Sci. Lett. 19 (2000) 1011-1014. 
doi:10.1023/A:1006753213286.

[20] ASTM C133, Standard test methods for cold crushing strength and modulus of rupture of refractories, Annu. B. ASTM Stand. 97 (2014) 1-6. doi:10.1520/C0133-97R08E01.2.

[21] A.H.Rashed, Properties and characteristics of Silicon Carbide, POCO Graph. Inc. Decatur. (2002).

[22] C. Walter, S. Barg, N. Ni, R.C. Maher, E. García-Tuñón, M.M. Zaiviji Ismail, F. Babot, E. Saiz, A novel approach for the fabrication of carbon nanofibre/ceramic porous structures, J. Eur. Ceram. Soc. 33 (2013) 23652374. doi:10.1016/j.jeurceramsoc.2013.04.024.

[23] J.-H. Eom, Y.-W. Kim, S. Raju, Processing and properties of macroporous silicon carbide ceramics: A review, J. Asian Ceram. Soc. 1 (2013) 220-242. doi:10.1016/j.jascer.2013.07.003.

[24] C. Ferraro, E. Garcia-tuñon, V.G. Rocha, S. Barg, M.D. Fariñas, T.E.G. Alvarezarenas, G. Sernicola, Light and Strong SiC Networks, (2016) 1-10. doi:10.1002/adfm.201504051.

[25] P. Greil, T. Lifka, A. Kaindl, Biomorphic Cellular Silicon Carbide Ceramics from Wood: II. Mechanical Properties, J. Eur. Ceram. Soc. 18 (1998) 19751983. doi:10.1016/S0955-2219(98)00155-1.

[26] E. Litovsky, M. Shapiro, A. Shavit, Gas Pressure and Temperature Dependences of Thermal Conductivity of Porous Ceramic Materials: Part 2, Refractories and Ceramics with Porosity Exceeding 30\%, J. Am. Ceram. Soc. 79 (1996) 1366-1376. doi:10.1111/j.1151-2916.1996.tb08598.x.

[27] E. García-Tuñon, S. Barg, J. Franco, R. Bell, S. Eslava, E. D’Elia, R.C. Maher, F. Guitian, E. Saiz, Printing in three dimensions with Graphene, Adv. Mater. 27 (2015) 1688-1693. doi:10.1002/adma.201405046.

[28] J. Sun, L. Gao, Dispersing SiC powder and improving its rheological behaviour, J. Eur. Ceram. Soc. 21 (2001) 2447-2451. doi:10.1016/S09552219(01)00196-0.

[29] M.D. Sacks, T.-Y. Tseng, Preparation of SiO2 Glass from Model Powder Compacts: I, Formation and Characterization of Powders, Suspensions, and Green Compacts, J. Am. Ceram. Soc. 67 (1984) 532-537. doi:10.1111/j.1151-2916.1984.tb19165.x.

[30] U.G.K. Wegst, M. Schecter, A.E. Donius, P.M. Hunger, Biomaterials by freeze casting, Philos. Trans. R. Soc. A Math. Phys. Eng. Sci. 368 (2010) 20992121. doi:10.1098/rsta.2010.0014.

[31] E. Munch, E. Saiz, A.P. Tomsia, S. Deville, Architectural Control of FreezeCast Ceramics Through Additives and Templating, J. Am. Ceram. Soc. 92 (2009) 1534-1539. doi:10.1111/j.1551-2916.2009.03087.x.

[32] S. Deville, Freezing as a Path to Build Complex Composites, Science (80-. ). 311 (2006) 515-518. doi:10.1126/science.1120937.

[33] P. Greil, T. Lifka, A. Kaindl, Biomorphic cellular silicon carbide ceramics from wood: I. Processing and Microstructure, J. Eur. Ceram. Soc. 18 (1998) 1975-1983. doi:10.1016/S0955-2219(98)00155-1. 
[34] N. Al Nasiri, N. Ni, E. Saiz, J. Chevalier, F. Giuliani, L.J. Vandeperre, Effect of microstructure and grain boundary chemistry on slow crack growth in silicon carbide at ambient conditions, J. Eur. Ceram. Soc. 35 (2015) 22532260. doi:10.1016/j.jeurceramsoc.2015.02.020.

[35] M.F.Ashby, The properties of foams and lattices, Philos. Trans. R. Soc. A Math. Phys. Eng. Sci. 364 (2006) 15-30. doi:10.1098/rsta.2005.1678.

[36] S. Deville, S. Meille, J. Seuba, A meta-analysis of the mechanical properties of ice-templated ceramics and metals, Sci. Technol. Adv. Mater. 16 (2015) 43501. doi:10.1088/1468-6996/16/4/043501.

[37] R.G. Munro, Material Properties of a Sintered $\alpha$-SiC, J. Phys. Chem. Ref. Data. 26 (1997) 1195. doi:10.1063/1.556000.

[38] J. Seuba, S. Deville, C. Guizard, A.J. Stevenson, Mechanical properties and failure behavior of unidirectional porous ceramics, Sci. Rep. 6 (2016) 24326. doi:10.1038/srep24326.

[39] S.P. Timoschenko, J.M. Gere, Theory of Elastic stability, 2nd ed., McGrawHill International Book Company, 2007.

[40] B.S.M. Seeber, U.T. Gonzenbach, L.J. Gauckler, Mechanical properties of highly porous alumina foams, J. Mater. Res. 28 (2013) 2281-2287. doi:10.1557/jmr.2013.102. 